\title{
Precipitation Characteristics of an Abrupt Heavy Rainfall Event over the Complex Terrain of Southwest China Observed by the FY-4A Satellite and Doppler Weather Radar
}

\author{
Shanshan $\mathrm{Li}^{1}$, Guoping $\mathrm{Li}^{2,3, * \mathbb{C}}$, Xiaofang Wang ${ }^{1}, \mathrm{Chao} \mathrm{Li}^{1}$, Haizhi Liu ${ }^{4}$ and Gang $\mathrm{Li}^{5}$ \\ 1 Institute of Heavy Rain, China Meteorological Administration, Hubei Key Laboratory for Heavy Rain \\ Monitoring and Warning Research, Wuhan 430074, China; doublemountainli@outlook.com (S.L.); \\ tiaotiao98@163.com (X.W.); lic@whihr.com.com (C.L.) \\ 2 School of Atmospheric Science, Chengdu University of Information Technology, Chengdu 610225, China \\ 3 Ministry of Education \& Collaborative Innovation Center on Forecast and Evaluation of Meteorological \\ Disasters (CIC-FEMD), Nanjing University of Information Science \& Technology, Nanjing 210044, China \\ 4 Department of National Meteorological Centre, China Meteorological Administration, Beijing 100081, China; \\ Lhz1012@aliyun.com \\ 5 Department of Guizhou Meteorological Observatory, Guizhou Meteorological Bureau, \\ Guiyang 550002, China; lg0857@163.com \\ * Correspondence: liguoping@cuit.edu.cn; Tel.: +86-28-8596-6386
}

Received: 9 July 2020; Accepted: 4 September 2020; Published: 8 September 2020

check for updates

\begin{abstract}
On 22 July 2019, mesoscale convective systems (MCSs) with an abrupt heavy rainfall event (AHRE) hit Shuicheng County of Guizhou Province in Southwest China causing landslide and debris flow secondary disasters. The AHRE over the complex terrain of Shuicheng County had differences in location and intensity during two stages of the event. The two stages could be divided into different rainfall types (topographic rainfall and synoptic-weather-related rainfall) according to the spatiotemporal distribution and organization of MCSs based on surface and midlevel environmental field conditions. During the topographic rainfall stage, smaller meso- $\gamma$-scale $(2-20 \mathrm{~km})$ convective cells with lower echo-top heights $(6-10 \mathrm{~km})$ occurred along the windward slope of the primary mountain peak. During the synoptic-weather-related rainfall stage, a meso- $\beta$-scale $(20-200 \mathrm{~km})$ convective echo band with higher echo-top heights (10-14 km) occurred in the valley of the region. An adverse wind area (AWA) with distinct convergence of radar radial velocity existed over Shuicheng County. A formation mechanism analysis of the AHRE showed that topographic rainfall occurred in the warm and moist area, while synoptic-weather-related rainfall occurred due to local convergence and the intrusion of a cold tongue. Compared to the early stage, the cold tongue from the higher terrain superimposed over the warm sector at the base of major mountain ranges appeared to strengthen the rainfall.
\end{abstract}

Keywords: precipitation characteristics; abrupt heavy rainfall event; complex terrain; FY-4A satellite; Doppler weather radar

\section{Introduction}

In Southwest China, an abrupt heavy rainfall event (AHRE) is defined as a period of $3 \mathrm{~h}$ of rainfall $\geq 50 \mathrm{~mm}$ with at least one $1 \mathrm{~h}$ rainfall period of $\geq 20 \mathrm{~mm}$ during the successive three-hour period [1,2]. The Yunnan-Guizhou Plateau of Southwest China is dominated by complex terrain, which often experiences landslide and debris flow disasters when AHREs happen [3-5]. With the availability of long-term precipitation data based on gauge observations, several studies have focused 
on the climatological aspects of these events, such as the occurrence frequency, intensity, diurnal variations, and synoptic conditions [6,7]; however, most climatological studies focus on the synoptic and meso- $\alpha$-scale environmental conditions of this extreme heavy precipitation [8,9]. In addition to the large-scale environmental conditions, high-precipitation supercells caused by terrain-forced convection have been observed to produce flash floods [10]. Luo et al. [11] also showed that smaller storms with extreme heavy precipitation tend to occur more frequently in the mountains over the Yunnan-Guizhou Plateau, among the nine considered subregions in their study. The orographic influences on heavy rainfall have received widespread attention in China. Du and Chen [12] clarified that the boundary layer jet (below $1 \mathrm{~km}$ ) colliding with the coastal terrain over southern China may enhance convergence to amplify the convection initiation. Chen et al. [13] determined that shallow low-level eastward airflow plays a key role in convective cell formation on the east side of Fanjing Mountain in Guizhou. Additionally, complex terrains sometimes act as high-level heat sources to force local uplift along the slope of mountains [14]. Therefore, the topographic influences on the AHREs of smaller-scale convective systems deserve further analysis.

Since AHREs occur more abruptly and on small spatial scales [15], it is hard for both numerical weather prediction models and experienced forecasters to predict their timing and location, often leaving local governments and the public unprepared. Thus, an observational analysis by multiple detection methods could provide excellent support for better understanding the mechanisms of rain formation and improving weather forecasts for such AHREs. Rain gauges provide point-wise measurement data of precipitation at ground level with a high temporal frequency, but a limited spatial coverage is their biggest constraint [16]. Meteorological radars can easily monitor and provide information on the spatial distribution of the rainfall over larger areas [17]. Radar detection over complex terrain may be influenced by the topography itself [18], but the radar observations cannot be ignored in characterizing the orographic rain structure and its associated spatiotemporal scales $[16,19,20]$. The Himawari-8 satellite and ground-based dual-Doppler radar data were adopted to document the inner core evolution of Typhoon Meranti (2016) after its interaction with Taiwan's topography [21].

A landslide and debris flow at 13:20 UTC on 23 July 2019 in the southwest Chinese province of Guizhou was responsible for 43 deaths and 9 missing people when it devastated Jichang in southern Shuicheng County. This landslide was a secondary disaster of a rainstorm, and it has attracted great attention in China. This landslide event of Shuicheng County was selected as one of the top ten natural disasters in 2019 by the Chinese Ministry of Emergency Management. The associated AHRE with a maximum rain rate of $66 \mathrm{~mm} / \mathrm{h}$ happened from 09:00 to 16:00 (UTC) on 22 July 2019, one day before the landslide. The forecast of this event can be tested by the location and intensity of heavy rainfall in comparison with observational data. The global models from the China Meteorological Administration (CMA), European Center for Medium-Range Weather Forecasts (ECMWF), and the National Centers for Environmental Prediction (NCEP) have determined that large-scale models have difficulty resolving the location and occurrence of heavy rainfall over complex terrain (Figure A1 (Appendix A)). Additionally, the high-resolution $\left(0.1^{\circ} \times 0.1^{\circ}\right.$ horizontal $)$ mesoscale model of the Global/Regional Assimilation and Prediction Enhanced System (GRAPES_MESO) for operational forecasting in China has not resolved the location and intensity issue of heavy rainfall over complex terrain (Figure A2), which caused the forecasters' confusion about whether to release the hazard warnings in this region. In addition to this one case, it is a widespread natural disaster over the complex terrain region in China caused by AHREs, e.g., Zhouqu storm-triggered debris flow [4]. So, we decided to consider this case study carefully to determine how these events can be better predicted to mitigate future disasters.

The main goal of this study is to reveal the topographic precipitation and radar echo characteristics of AHREs under different environmental conditions according to the spatiotemporal distribution and organization of mesoscale convective systems (MCSs). The manuscript is organized as follows: Section 2 describes the data and methodology used in this study. The results are presented in Section 3: (1) providing detailed topography descriptions and the observed rain gauge precipitation, (2) tracking and considering the organization of the MCSs by combining the surface and midlevel environmental 
field conditions to classify two rainfall stages, (3) documenting radar precipitation characteristics during the two rainfall stages, and (4) using automatic weather station (AWS) data to briefly demonstrate the formation mechanism of the AHRE. A summary is given in Section 4.

\section{Data and Methodology}

\subsection{FY-4A Satellite}

FengYung-4A (FY-4A) is the newest generation of Chinese geostationary meteorological satellites with greatly enhanced capabilities for high-impact weather event monitoring, warning, and forecasting [22]. The observational parameters and main sensors of FY-4A are presented in Table 1. FY-4A carries four new instruments (Table 1) that will be used to improve applications in a wide range of ocean, land, and atmosphere monitoring as well as extreme weather forecasting. In this study, we used the blackbody brightness temperature (TBB, http://satellite.nsmc.org.cn/) of the FY-4A infrared channel of $10.8 \mu \mathrm{m}$ from the Advanced Geosynchronous Radiation Imager (AGRI) at a $4 \mathrm{~km}$ horizontal resolution and $10 \mathrm{~min}$ ( $5 \mathrm{~min}$ ) in full-disk (China region) temporal resolution to identify and track MCSs. The identification and tracking algorithm of the MCSs was defined based on previous studies $[23,24]$.

The detection criteria are as follows. (1) The TBB threshold (TBB $\leq 221 \mathrm{~K}$ ) is used to identify the areas of the MCSs, and the cloud area should be no less than $5000 \mathrm{~km}^{2}$. (2) The duration of the MCSs should be no shorter than $3 \mathrm{~h}$; (3) the propagating MCS is tracked by identifying areas that overlap more than $50 \%$ within two successive TBB images. The ratio of the overlapping area can be calculated in two steps: (a) identify the same longitude and latitude pixels in the two successive MCSs and (b) then calculate the percentage of the pixels that are the same as in the previous MCSs. (4) Finally, when two or more systems merge together, the largest overlapped system is assumed to continue, and the smaller overlapped systems are terminated. Similarly, when a cloud system splits into several smaller systems, the largest overlapped fragment continues carrying on the characteristics of the original system, and the smaller overlapped fragments are labeled as newly formed clouds.

Additionally, the minimum TBB, radius, and circularity of the MCSs, are also calculated according to these criteria. The radius is defined as the equivalent radius of a circle $(\mathrm{R})$, such that the area is given by $A=\pi R^{2}$. The circularity is defined as the shape of the MCSs, given by $C=A / P$, where $P$ is the perimeter.

Table 1. The observation parameters and main sensors of FY-4A.

\begin{tabular}{cc}
\hline Parameters & Descriptions \\
\hline Stabilization & Three-axis \\
\hline Designed Life & 7 Years (Designed life) \\
\hline Observation Efficiency & $85 \%$ \\
\hline Observation Mode & Imaging + Sounding + Lightning Maping \\
\hline & 1. Advanced Geosynchronous Radiation Imager (AGRI) is used to obtain the \\
& radiation image of surface, atmosphere and cloud; \\
\cline { 2 - 3 } Main Sensors & $\begin{array}{c}\text { 2. Geosynchronous Interferometric Infrared Sounder (GIIRS) is used to obtain } \\
\text { atmosphere temperature and humidity profiles under clear sky conditions; }\end{array}$ \\
\cline { 2 - 3 } & $\begin{array}{c}\text { 3. Lightning Mapping Imager (LMI) is used to obtain lightning distribution in } \\
\text { China and its surrounding areas; }\end{array}$ \\
\cline { 2 - 3 } & $\begin{array}{c}\text { 4. Space Environment Package (SEP) is used to obtain space electromagnetic } \\
\text { environment and space weather effect information in geosynchronous orbit. }\end{array}$ \\
\hline
\end{tabular}




\subsection{Doppler Weather Radar}

Four C-band Doppler weather radars in the region operate on a $5 \mathrm{~cm}$ wavelength and provide nine unique elevation scans every $6 \mathrm{~min}$. The beam widths of the four Doppler radars are $1^{\circ}$ and the physical widths of the beam 100-200 km from Shuicheng County are more than $1 \mathrm{~km}$ (about 1.74-3.49 km). In this study, we used two sets of radar data, namely (1) the three-dimensional mosaic production derived from four radars and (2) the data from the Xingyi radar. This mosaic dataset was produced by the Institute of Heavy Rain (IHR) [25], which has been used to identify convective systems [26]. The quality control method of individual radar data was mainly based on a fuzzy-logic algorithm to remove ground clutter [27], and the improved three-step postprocessing algorithm of the dual pulse repetition frequency (dual PRF) technique was used for the quality control of the radial velocity [28]. For the three-dimensional mosaic method, we (1) calculated the elevation, azimuth, and range using the longitude, latitude, and height under Cartesian coordinates; (2) used nearest-neighbor interpolation methods on range-azimuth planes combined with linear interpolation in the vertical direction to remap volumetric radar data from polar coordinates onto fine mesh grids $\left(0.01^{\circ} \times 0.01^{\circ}\right.$ horizontal and $0.5 \mathrm{~km}$ vertical spacing) under Cartesian coordinates; (3) remapped the reflectivity fields from multiple radars onto a common Cartesian grid by using an exponential distance-weighting function; (4) set the interval time to remap multiple radars onto a common grid to be no greater than six minutes. The composite reflectivity and echo top height were obtained from the three-dimensional mosaic data set. The composite reflectivity was calculated by the vertical maximum reflectivity in all vertical levels. The echo top height was calculated from the height of $18 \mathrm{dBZ}$ reflectivity [29].

Additionally, our study used the monitoring network of more than 1500 AWSs over the Yunnan-Guizhou Plateau in $10 \mathrm{~min}$ intervals to provide the surface precipitation, wind, temperature, and moisture fields. To analyze the MCS activities and related synoptic-weather systems, we used the latest ECMWF atmospheric reanalysis ERA5 (https://cds.climate.copernicus.eu/cdsapp\#!/home) with a horizontal resolution of $0.25^{\circ} \times 0.25^{\circ}$ and a time interval of $1 \mathrm{~h}$.

\section{Results}

\subsection{Topography and Observed Precipitation}

In Figure 1a, the Yunnan-Guizhou Plateau is the second-step terrain in the downstream region of Qinghai-Tibet Plateau (the first-step terrain). Shuicheng County is located in the eastern part of the Yunnan-Guizhou Plateau and is characterized by local complex terrain due to the Wumeng Mountains. The southwest boundary of Shuicheng County is dominated by the Niupengliangzi main peak with a height of $2865 \mathrm{~m}$, and the middle part of the county is also occupied by higher terrain, with heights exceeding $2300 \mathrm{~m}$. The southern area of Shuicheng County is located between two higher terrain areas with heights exceeding $2000 \mathrm{~m}$, but the altitude of the southeastern part is less than $1750 \mathrm{~m}$ and has a narrow entrance with a height less than $1000 \mathrm{~m}$. Therefore, Shuicheng County forms a typical "bellmouth" topography with a narrow southeastern airflow entrance between two higher terrain regions (Figure 1a). This "bellmouth" topography interacts with the easterly air flow, thereby creating favorable conditions for topographic rainfall. The landslide point of Jichang is located in the northern slope of the Niupengliangzi main peak, and the landslide and debris flow have a southwest-northeast trend from the hillside (Figure 1b). The geological and hydrological settings of Shuicheng County are vital for gaining a greater understanding of this landslide event. 
(a)

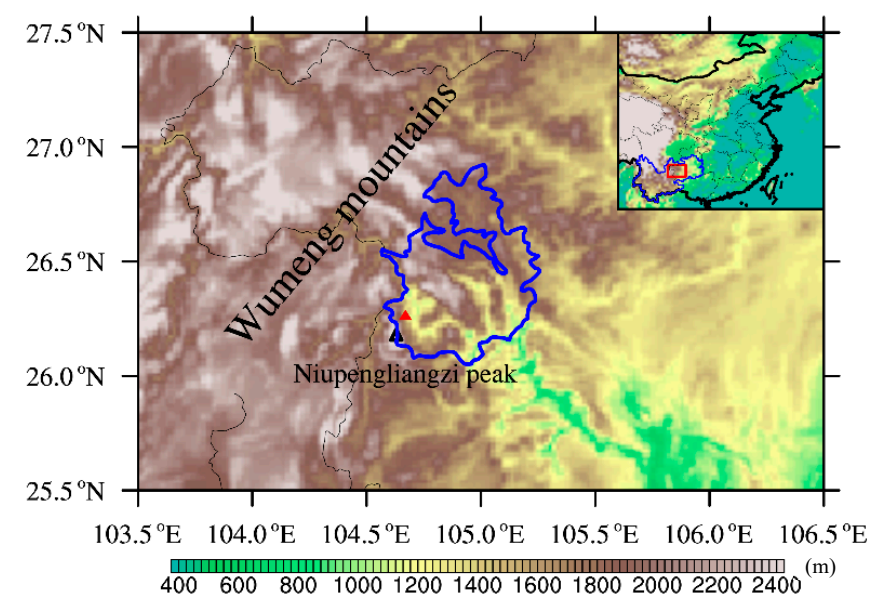

(b)

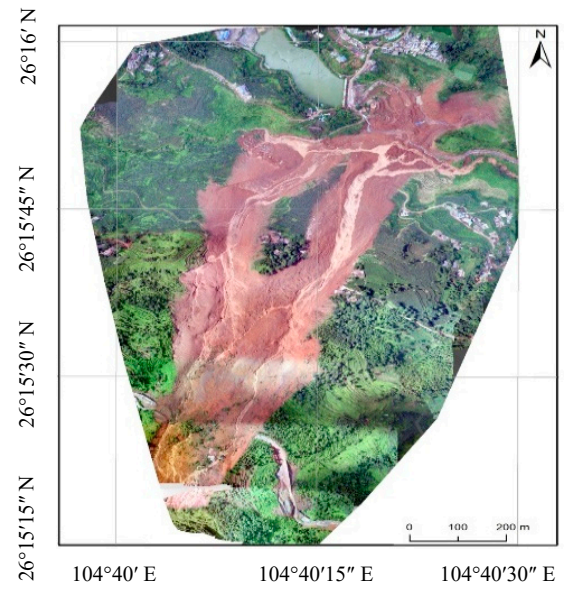

Figure 1. (a) The topographical distribution of the Wumeng Mountains and (b) an image of the Shuicheng County landslide and debris flow of 23 July 2019 after cessation, Source: Guizhou Earthquake Administration (http://www.gzsdzj.gov.cn/xygl/yjcz/201907/t20190726_5304724.html). The red solid triangle represents the location of the landslide; Shuicheng County is outlined in blue. In the inset map of panel (a), the Yunnan-Guizhou Plateau is outlined in blue, and the area of interest is outlined with a red box.

From 09:00 to 16:00 UTC on 22 July, a sudden rainstorm with a shorter duration occurred in the complex terrain of Shuicheng County; Figure 2 shows the hourly accumulated precipitation and topographic characteristics during the AHRE. The slope of the main peak is the transitional zone with a higher altitude gradient (e.g., red circle in Figure 2a), while the valley regions have relatively flat areas between the higher terrains (e.g., blue circle in Figure 2e). It can be seen that a $1 \mathrm{~h}$ rainfall amount $\geq 20 \mathrm{~mm}$ occurred from 09:00 to 10:00 UTC on 22 July, but only one station with a rainfall amount of $39.9 \mathrm{~mm}$ was located in the windward slope of the Niupengliangzi main peak (red circle area in Figure 2a). From 10:00 to 11:00 UTC, three stations located in the slope of the middle main peak of Shuicheng County had $1 \mathrm{~h}$ rainfall amounts of $\geq 20 \mathrm{~mm}$. From 11:00 to 12:00 UTC, a west-east rainstorm belt was apparent in northern Shuicheng County at $26.6^{\circ} \mathrm{N}$. In addition, there were three isolated stations in the southern part of the rainstorm belt: two stations in the slope of the Niupengliangzi main peak and another station in southeastern Shuicheng County that recorded rainfall in excess of $20 \mathrm{~mm} / \mathrm{h}$. Here, the station $5.4 \mathrm{~km}$ south of the landslide point had a $1 \mathrm{~h}$ rainfall amount of $25.4 \mathrm{~mm}$ and a $3 \mathrm{~h}$ rainfall amount of $65.3 \mathrm{~mm}$ from 09:00 to 11:00 UTC, which satisfied the conditions for an AHRE in the windward slope of the Niupengliangzi main peak (red circle area in Figure 2c). From 12:00 to 13:00 UTC, the blue-colored stations with $1 \mathrm{~h}$ rainfall amounts $\geq 20 \mathrm{~mm}$ increased rapidly and showed a northwest-southeast orientation band in the valley region between the major mountain ranges, such as two stations with $1 \mathrm{~h}$ rainfall amounts $\geq 20 \mathrm{~mm} 10 \mathrm{~km}$ north of the landslide point. From 13:00 to 14:00 UTC, the $1 \mathrm{~h}$ rainfall amount increased suddenly in the valley region, and four stations within the $8 \mathrm{~km}$ to the east of the landslide point recorded more than $50 \mathrm{~mm}$ of rain (blue circle area in Figure 2e), while there was no obvious heavy rainfall in the slope of the main peak (red circle area in Figure 2a). From 14:00 to 15:00 UTC, stations exceeding $20 \mathrm{~mm}$ decreased rapidly in the valley region, but, since stations had still previously recorded more than $50 \mathrm{~mm}$ of rain in the valley near the landslide location, the AHRE conditions were still satisfied. From the spatiotemporal distribution of the rainstorm, it can be seen that there were two rainfall stages in center Shuicheng County: an isolated rainfall in the slope of the main peak during the early stage (Figure 2a-c) and a stronger rainfall band located in the valley between the major mountain ranges during the later stage (Figure $2 \mathrm{~d}-\mathrm{f}$ ). 
(a)

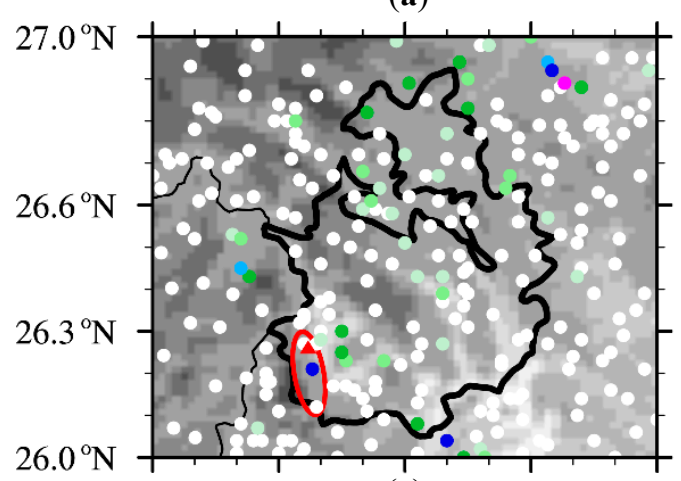

(c)

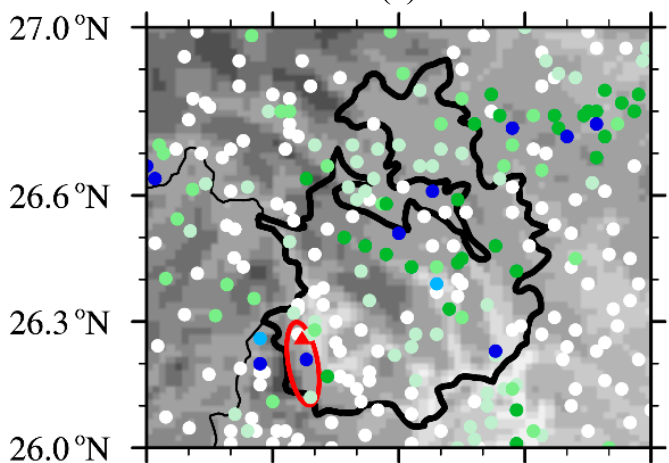

(e)

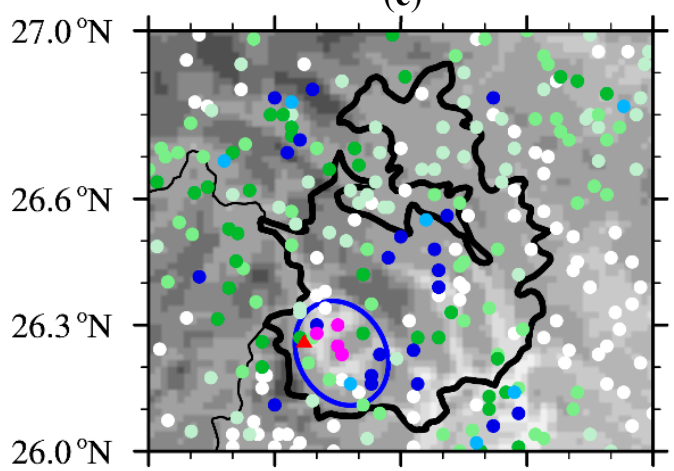

$104.3^{\circ} \mathrm{E} 104.6^{\circ} \mathrm{E} 104.9^{\circ} \mathrm{E} 105.2^{\circ} \mathrm{E} 105.5^{\circ} \mathrm{E}$

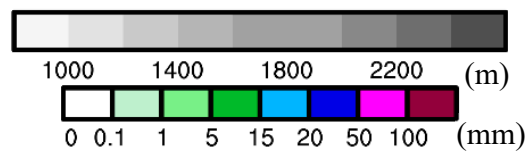

(b)

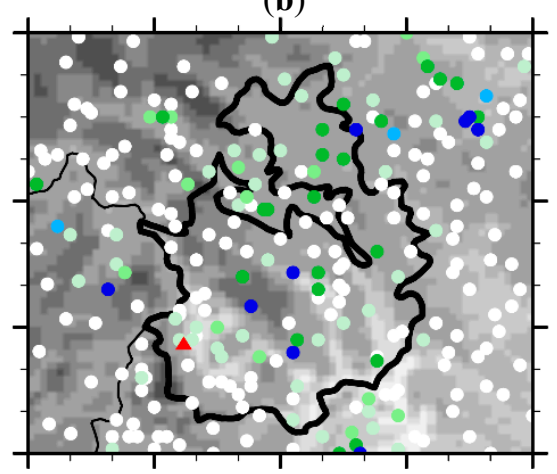

(d)

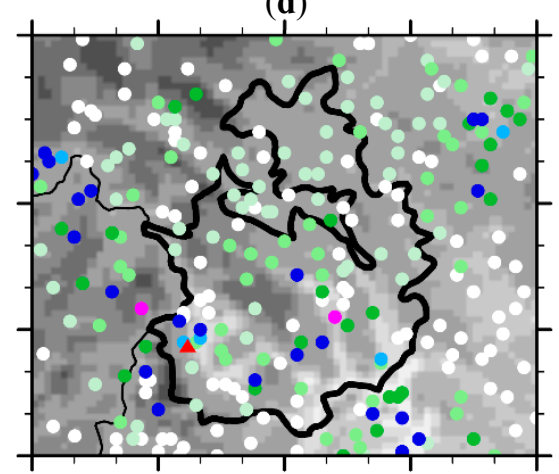

(f)

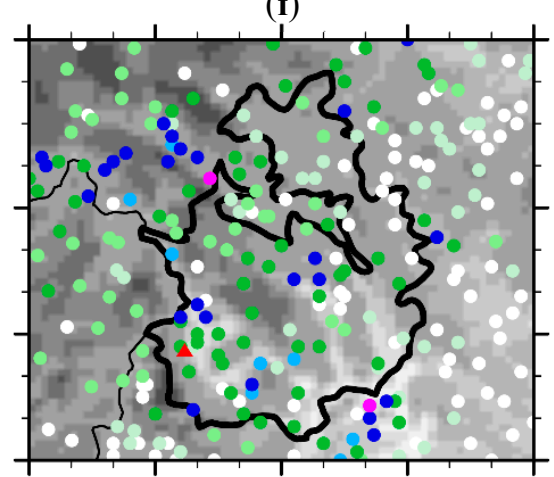

E104.3 ${ }^{\circ} \mathrm{E} 104.6^{\circ} \mathrm{E} 104.9^{\circ} \mathrm{E} 105.2^{\circ} \mathrm{E} 105.5^{\circ} \mathrm{E}$

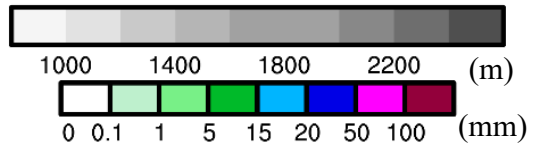

Figure 2. The hourly accumulated precipitation evolution observed by automatic weather stations and topographic characteristics in Shuicheng County (shaded, m). (a) From 09:00 to 10:00 UTC; (b) from 10:00 to 11:00 UTC; (c) from 11:00 to 12:00 UTC; (d) from 12:00 to 13:00 UTC; (e) from 13:00 to 14:00 UTC; (f) from 14:00 to 15:00 UTC on 22 July 2019. The colored dots represent different levels of precipitation; the red solid triangle represents the location of the landslide.

\subsection{Tracking and Organization of the MCSs}

The propagation process of MCSs is very complicated and includes multiple cloud cluster movements, extinction, regeneration, merging, and splitting [26,30]. Figure 3a depicts the MCS centroid locations and their propagation paths over Southwest China objectively. The MCSs formed in the southern part of Sichuan Basin at 19:00 UTC on 21 July and then propagated eastward until 13:00 UTC on 22 July. Afterwards, the MCSs split into two parts located in either Chongqing or the Yunnan-Guizhou Plateau. The southern part of the MCSs had a longer duration of $7 \mathrm{~h}$, which appeared to have southeastward and then westward propagation in the Yunnan-Guizhou 
Plateau. Figure 3b depicts the evolution of the MCS, which formed with a radius of $69 \mathrm{~km}$ before growing significantly to its maximum radius of $309 \mathrm{~km}$ at 09:00 UTC on 22 July; this was the strongest stage of the MCS, corresponding to a minimum TBB of 186 K. Between 06:00 and 09:00 UTC, the MCS grew substantially but decreased in circularity, which suggests that it merged with southern banded convective systems, lost its circular shape (Figure 3c), and evolved into a more complicated structure (Figure 3d). At 14:00 UTC, this MCS split into two components, with properties of the southern part still present in Figure 3b. At this point, the southern MCS over Yunnan-Guizhou Plateau reached Shuicheng County and its strongest stage again, with a minimum TBB of $186 \mathrm{~K}$. Figure $3 \mathrm{c}-\mathrm{f}$ provides infrared images of the TBB and the corresponding 10 min accumulated precipitation. In Figure 3d, there were two rainbands in the southern MCS: a northern rainband along its northern edge and a southern small-scale rainband in Shuicheng County, $200 \mathrm{~km}$ south of the main rain belt. At 13:40 UTC, the banded MCS split into two parts, and the southern MCS adopted an east-west orientation in the Yunnan-Guizhou Plateau. Meanwhile, the northern edge of the southern MCS with the main rain belt hit Shuicheng County. At 18:30 UTC, the southern MCS moved westwards, and the heavy rainfall weakened in Shuicheng County. The main rain belt was located along the northern edge of the identified banded MCSs (northern ellipses in Figure 3d,e), while a small-scale local rainband occurred in front of the banded MCSs over complex terrain (southern ellipses in Figure 3d). However, the small-scale local rainband over complex terrain in Shuicheng County is difficult to predict by the large-scale and mesoscale numerical models (Figures A1 and A2).

(a)

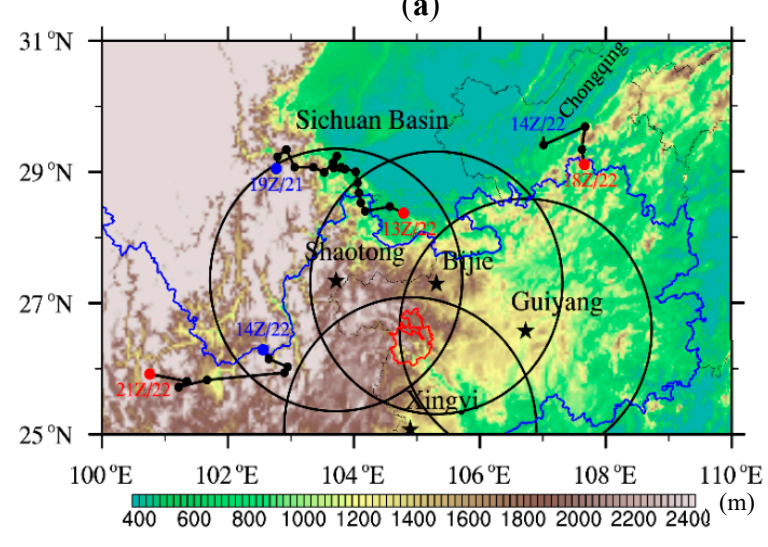

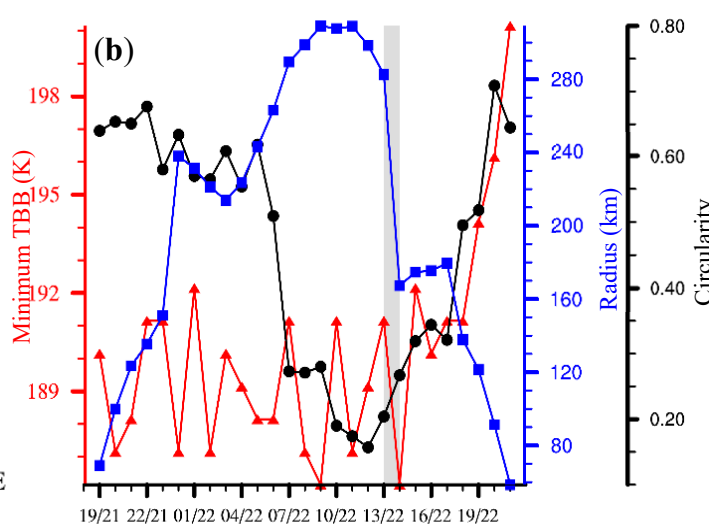

Time (hour/day)

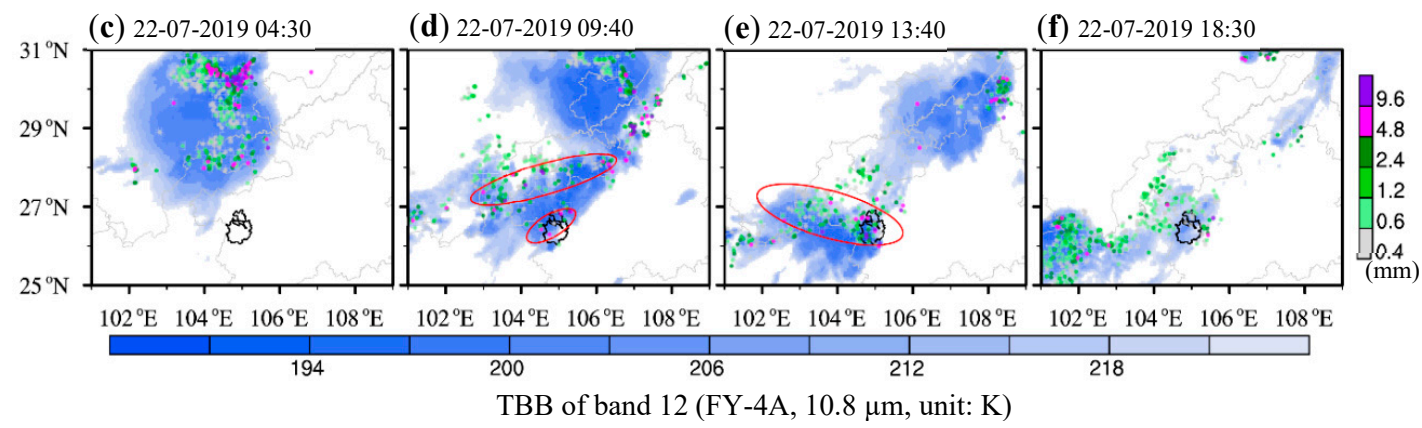

Figure 3. (a) The locations and propagations of mesoscale convective systems (MCSs) over Southwest China. The MCS centroids are denoted by solid circles with accompanying time labels (hour/day UTC); the blue spots represent onset locations, and the red spots represent dissipation locations. The locations of the four radars are denoted by solid stars; the radius of the range rings is $200 \mathrm{~km}$. The Yunnan-Guizhou Plateau area is outlined with a blue line, and Shuicheng County is outlined with a red line. (b) The minimum blackbody brightness temperature (TBB), radius, and circularity evolution of the MCSs. The gray shaded area represents the moment the MCSs split. (c-f) The infrared images of TBB observed by the FY-4 satellite and overlaid by the future $10 \mathrm{~min}$ accumulated precipitation. The colored dots represent different levels of precipitation, and the red circles denote the rainfall bands. 
The MCSs may take on different types of organization in regions with different environmental conditions [31]. In this study, we describe the organization of the convective cloud clusters in the MCSs by combining the surface and midlevel environmental field conditions to evaluate the two heavy rainfall stages in Shuicheng County. To show the overall convective characteristics in the MCSs clearly, the convective cloud cluster in the satellite images and corresponding radar composite reflectivity under different environmental field conditions are shown in Figure 4. At 09:00 UTC, during the early rainfall stage, a banded convective cloud cluster with a northeast-southwest orientation was located on the northwest edge of Shuicheng County. At this point, the body of this MCS had not moved into Shuicheng County, and Shuicheng County was dominated by southwesterly winds with no obvious synoptic-weather system present (Figure 4a). However, southeasterly warm and moist air at the surface flowed into the "bellmouth" topography, which contributed to the topographic rainfall in Shuicheng County (Figure $4 \mathrm{~b}$ ). In addition, the obvious vertical shear environment of the horizontal winds over Shuicheng County from the surface to $700 \mathrm{hPa}$ favored the formation of topographic convection [32]. At 12:00 UTC, before the later rainfall stage happened, convective cloud clusters in the MCSs had organized into a west-east oriented band that corresponded to an intense radar echo belt in the northwestern and northeastern areas of Shuicheng County. Meanwhile, a low-vortex weather system of cyclonic winds at $700 \mathrm{hPa}$ (the "L" in Figure 4c) formed in the southwest of Shuicheng County, and a stronger airflow convergence line occurred in the northern area of this low-vortex. Here, the convergence zone of the surface wind fields had moved southwards (Figure 4d). At 14:00 UTC, during the later rainfall stage, a convective cloud band moved southwards and formed an intense cold core high over Shuicheng County. This intense cold core developed into its strongest stage in Figure 3b, with a minimum TBB of $186 \mathrm{~K}$ and a cloud-top height of 17,100 m. Meanwhile, the low-vortex enhanced and moved southwards, and stronger southeasterly winds flowed into Shuicheng County. The stronger convective echo belt was located in the northeastern area of the midlevel low-vortex (Figure 4e). In the surface environmental field, the convergence zone was pushed to the southern border of Shuicheng County, and cold air hit the southern region of Shuicheng County (Figure 4f).

According to the spatiotemporal evolution and organizational characteristics of the MCSs, using both the surface and midlevel environmental field conditions, we could conclude that two stages of heavy rainfall in Shuicheng County occurred with different rainfall types. During the early stage, the body of the banded MCSs was located in the northwest of Shuicheng County, while the southeasterly warm and moist air at the surface in front of the MCSs flowing into the "bellmouth" topography caused topographic rainfall. During the later stage, the banded MCSs split into two parts, and the southern MCS with an intense cold core hit Shuicheng County. The AHRE at this stage was related to the environmental conditions of the $700 \mathrm{hPa}$ low-vortex and the surface cold and warm air convergence zones, i.e., the synoptic-weather-related rainband. 
(a)

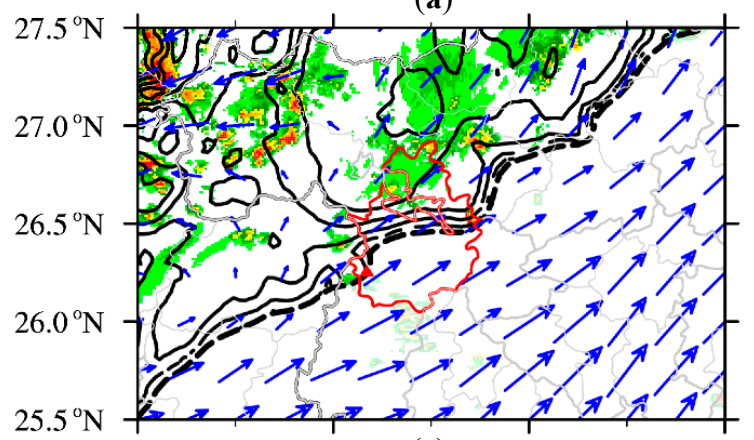

(c)

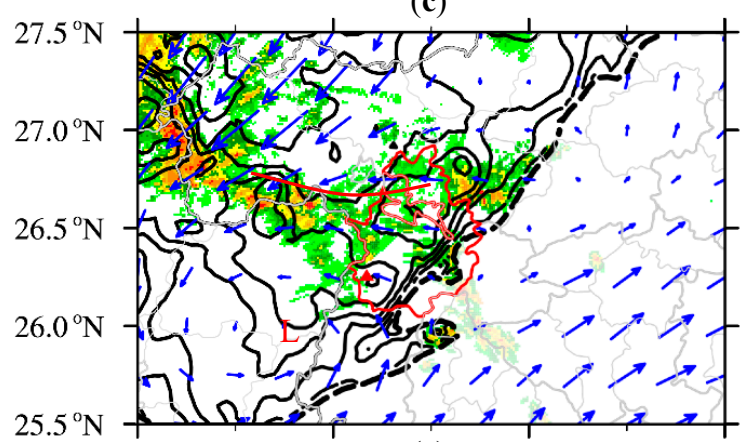

(e)

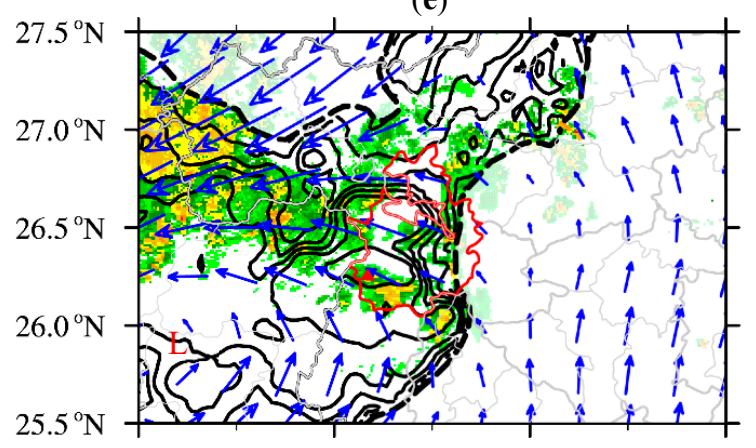

$103.5^{\circ} \mathrm{E}$

$04.5^{\circ} \mathrm{E}$

$105.5^{\circ} \mathrm{E} \quad 106.5^{\circ} \mathrm{E}$

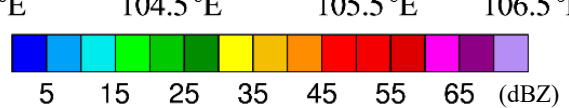

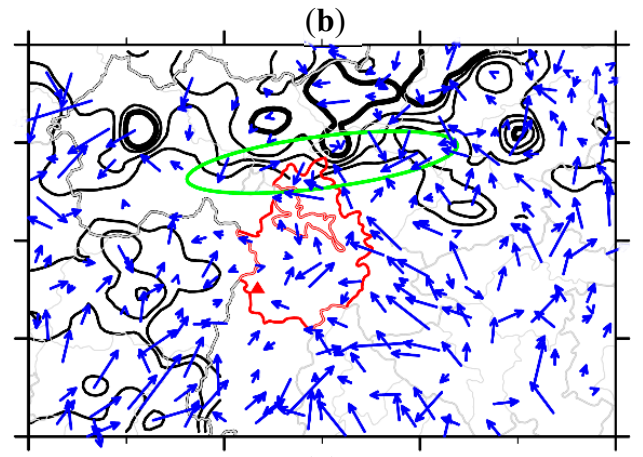

(d)

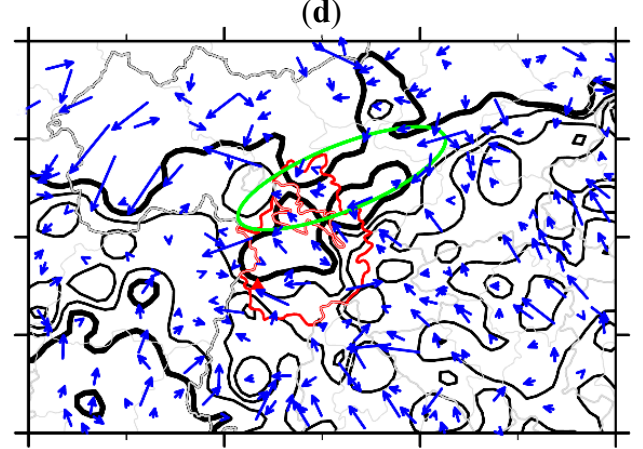

(f)
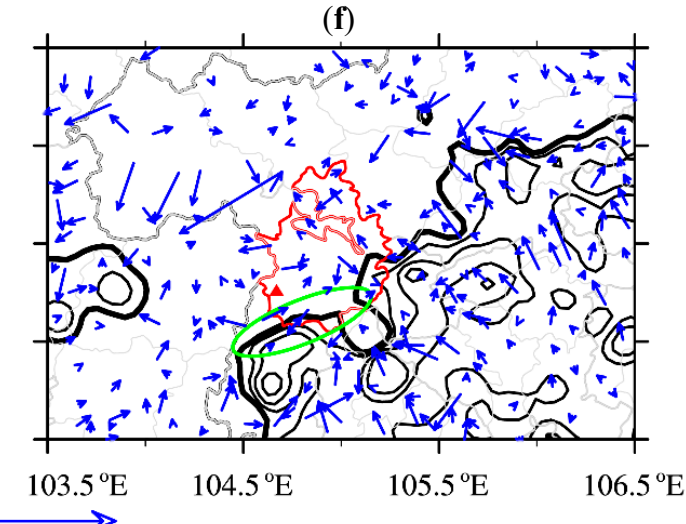

Figure 4. (Left panel) Radar composite reflectivity (shaded, dBZ) overlaid by the FY-4 satellite TBB (contours, K) and horizontal wind vectors (vectors, $\mathrm{m} / \mathrm{s}$ ) at $700 \mathrm{hPa}$ from ERA5 reanalysis data; (right panel) $\theta_{\mathrm{e}}$ (contours, unit: K) overlaid by surface winds (vectors, m/s) at (a,b) 09:00 UTC; (c,d) 12:00 UTC; (e,f) 14:00 UTC on 22 July 2019. The black dotted lines in the left panel represent the $221 \mathrm{~K}$ isolines of the identified MCSs (region with TBB $\leq 221 \mathrm{~K}$ ). The TBB is contoured at intervals of $5 \mathrm{~K}$. The red solid lines denote the convergence line, and "L" denotes a low-vortex system. The light-shaded colors are the composite reflectivity values outside the MCSs. The thick black solid lines in the right panel represent the value of $356 \mathrm{~K}$ in the $\theta_{\mathrm{e}}$ fields and $2 \mathrm{~K}$ contour intervals.

\subsection{Precipitation Characteristics Observed by Doppler Radar}

Radar detection over the Yunnan-Guizhou Plateau may be influenced by complex terrain, so it is important to determine how the observation capacity and precipitation characteristics from Doppler radar differ during the two rainfall stages. Consider the evolution of the radar composite reflectivity and echo-top height from the three-dimensional mosaic dataset in detail to evaluate the terrain precipitation (in Figures 5 and 6). In this study, we used the maximum composite reflectivity within one hour to avoid the randomness of time selection, allowing the radar reflectivity to be closer to the distribution of the hourly accumulated precipitation [33]. Shinoda et al. [34] demonstrated that convective cells ( $\geq 30 \mathrm{dBZ}$ ) with low echo-top heights less than $1 \mathrm{~km}$ above the environmental $0{ }^{\circ} \mathrm{C}$ 
level have typical horizontal scales of less than $20 \mathrm{~km}$ (meso- $\gamma$-scale). The height of the environmental $0{ }^{\circ} \mathrm{C}$ level is about $6 \mathrm{~km}$ over Shuicheng County from the adjacent sounding station (not shown). The uncertainty on the echo top height from a single radar at $100 \mathrm{~km}$ range in our study region is about $2 \mathrm{~km}$. The three-dimensional mosaic from four radars could reduce this uncertainty, but it still remains. So, we defined the low echo top heights for convective cells as less than $10 \mathrm{~km}$ in this study.

During the topographic rainfall stage (Figures $5 \mathrm{a}-\mathrm{c}$ and $6 \mathrm{a}-\mathrm{c}$ ), there are several isolated meso- $\gamma$-scale $(2-20 \mathrm{~km})$ convective cells with lower echo-top heights $(6-10 \mathrm{~km})$ that occurred in the slope of the main peak. From 09:00 to 10:00 UTC, a separate convective cell " $\mathrm{A}$ " with reflectivity values over $30 \mathrm{dBZ}$ and an echo-top height of about 6-10 km was collocated with a $1 \mathrm{~h}$ rainfall amount of $39.9 \mathrm{~mm} 5 \mathrm{~km}$ south of the landslide point. The convective cells " $\mathrm{B}$," " $\mathrm{C}$," " $\mathrm{D}$," and " $\mathrm{E}$ " also have lower echo-top heights of about $6-10 \mathrm{~km}$ in the windward slope of the main peak. In addition to the convective cells, there was an obvious convective band with a higher echo-top height (10-14 km) located in the northern part of the topographic rainfall area, which was caused by surface convergence (Figure 4b). From 10:00 to 11:00 UTC, cells " $\mathrm{A}$ " through " $\mathrm{D}$ " had moved northeastwards and merged into the stronger convective cells " $\mathrm{A}+\mathrm{B}$ " and " $\mathrm{C}+\mathrm{D}$ " due to the $700 \mathrm{hPa}$ southwesterly winds over the topographic rainfall area (Figure $4 \mathrm{a}$ ). The cells " $\mathrm{A}+\mathrm{B}$ " and " $\mathrm{C}+\mathrm{D}$ " were collocated with two distinct rainfall centers of $1 \mathrm{~h}$ rainfall amounts $\geq 20 \mathrm{~mm}$ in the slope of the middle main peak, and the composite reflectivity of cell " $\mathrm{C}+\mathrm{D}$ " reached $45 \mathrm{dBZ}$ with an echo-top height of $10 \mathrm{~km}$ in the narrow southeasterly airflow entrance area. Moreover, the synoptic-weather-related echo band in northern Shuicheng County moved southwards and approached the topographic rainfall area. From 11:00 to 12:00 UTC, cells " $\mathrm{A}+\mathrm{B}$ " and " $\mathrm{C}+\mathrm{D}$ " continued to moved northeastwards, and cells " $\mathrm{C}+\mathrm{D}$ " and " $\mathrm{E}$ " had merged into a convective cell with a $1 \mathrm{~h}$ rainfall amount of $\geq 20 \mathrm{~mm}$. In the meantime, there was a new convective cell " $\mathrm{F}$ " formed on the eastern slope of the Niupengliangzi main peak. The synoptic-weather-related echo band had moved to the middle of Shuicheng County. During the synoptic-weather-related rainfall stage (Figures $5 \mathrm{~d}-\mathrm{f}$ and $6 \mathrm{~d}-\mathrm{f})$, there were obvious meso- $\beta$-scale $(20-200 \mathrm{~km})$ convective bands with higher echo-top heights (10-14 km) in Shuicheng County. From 12:00 to 13:00 UTC, cells "A + B" and "C $+\mathrm{D}+\mathrm{E}$ " during the topographic rainfall stage had merged into a synoptic-weather-related echo band with a northwest-southeast orientation, which corresponded to the banded rainfall with a $1 \mathrm{~h}$ rainfall amount of $\geq 20 \mathrm{~mm}$ in the valley between the major mountain ranges. The echo-top height reached $14 \mathrm{~km}$ in the south of echo belt. From 13:00 to 14:00 UTC, the echo belt moved southwards and passed through the valley of Shuicheng County. It can be seen that an area of composite reflectivity exceeding $35 \mathrm{dBZ}$ increased in the valley, with the location of the landslide located just west of the echo belt location. Four weather stations recorded hourly accumulated rainfall amounts of more than $50 \mathrm{~mm}$ with weaker recorded reflectivity values than those of the band to the east because of the beam blockage from the Niupengliangzi main peak. The echo-top heights of composite reflectivity exceeding $30 \mathrm{dBZ}$ were about 10-14 km in the valley region. From 14:00 to 15:00 UTC, the echo belt with a higher echo-top height continued to move southwards to the south of the landslide point. From the above analysis, it seems that Doppler radar should have been able to observe the same precipitation characteristics obtained over Shuicheng County in Section 3.1; however, beam blockage in the region reduced the intensity of the radar reflectivity. 
(a)

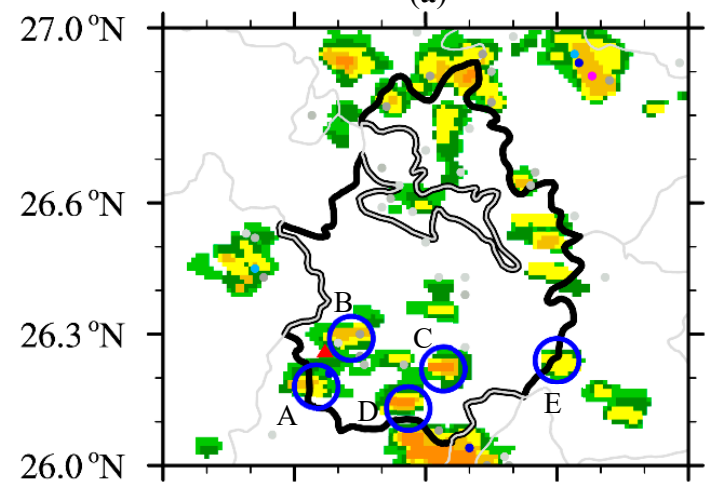

(c)

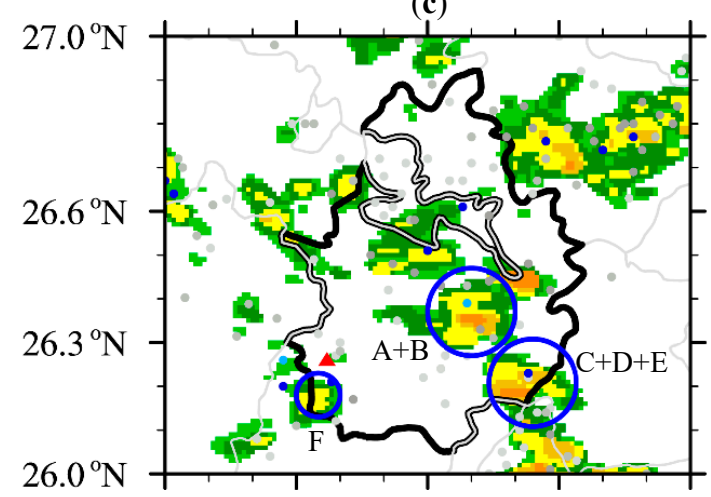

(e)

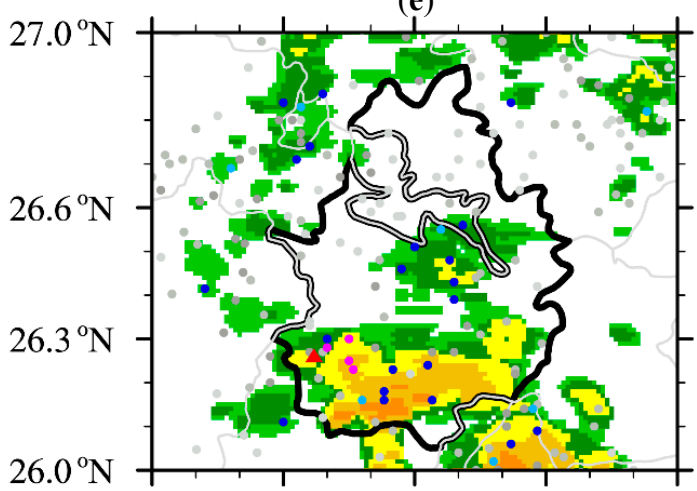

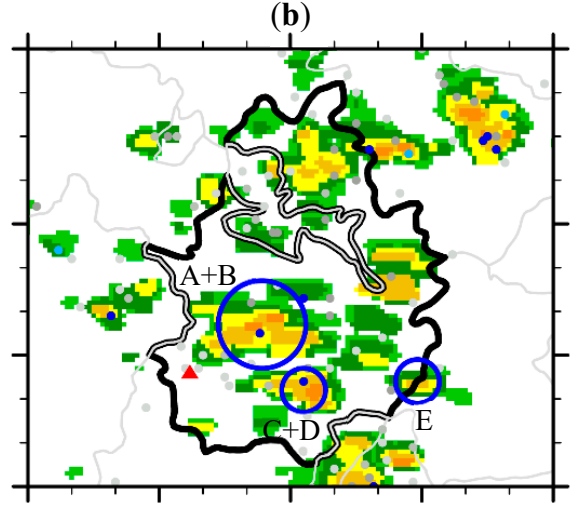

(d)

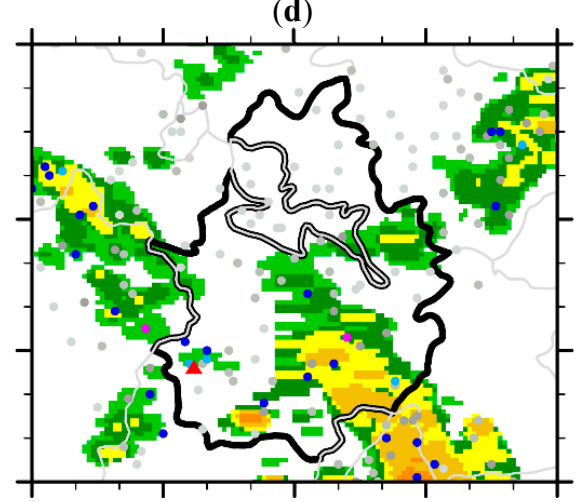

(f)

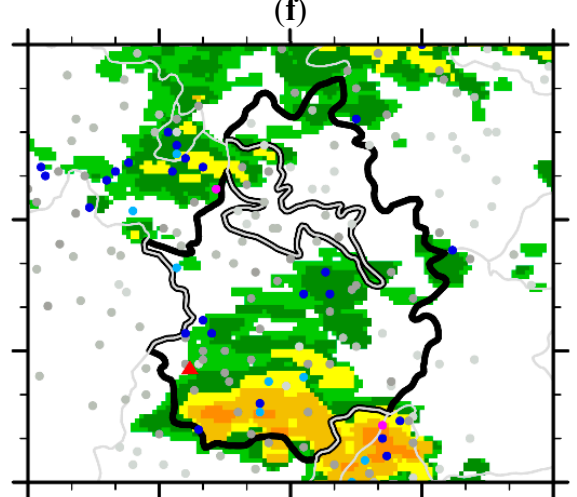

$104.3^{\circ} \mathrm{E} 104.6^{\circ} \mathrm{E} 104.9^{\circ} \mathrm{E} 105.2^{\circ} \mathrm{E} 105.5^{\circ} \mathrm{E} 104.3^{\circ} \mathrm{E} 104.6^{\circ} \mathrm{E} 104.9^{\circ} \mathrm{E} 105.2^{\circ} \mathrm{E} 105.5^{\circ} \mathrm{E}$
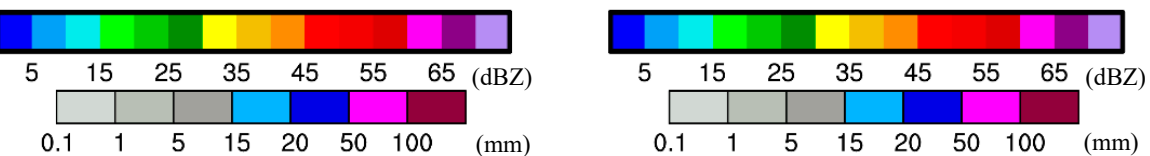

Figure 5. Radar maximum composite reflectivity of three-dimensional mosaic data (shaded, dBZ) overlaid by $1 \mathrm{~h}$ accumulated rainfall (colored dots, $\mathrm{mm}$ ) near Shuicheng County (a) from 09:00 to 10:00 UTC; (b) from 10:00 to 11:00 UTC; (c) from 11:00 to 12:00 UTC; (d) from 12:00 to 13:00 UTC; (e) from 13:00 to 14:00 UTC; (f) from 14:00 to 15:00 UTC on 22 July 2019. The letters in the panels represent the convective cells referenced in the main text. 
(a)

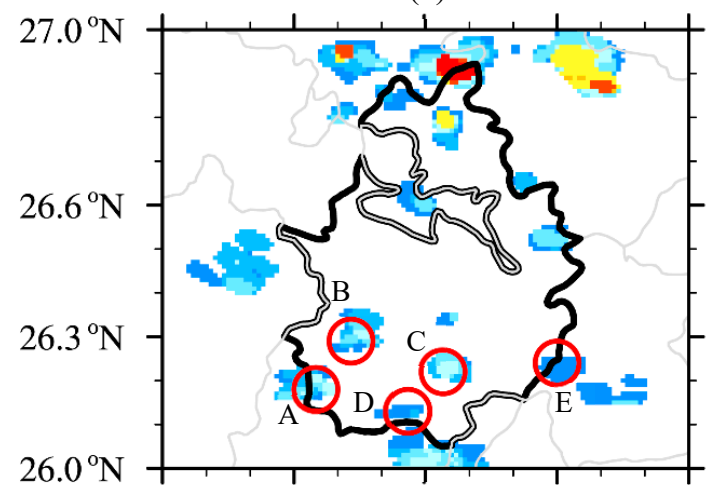

(c)

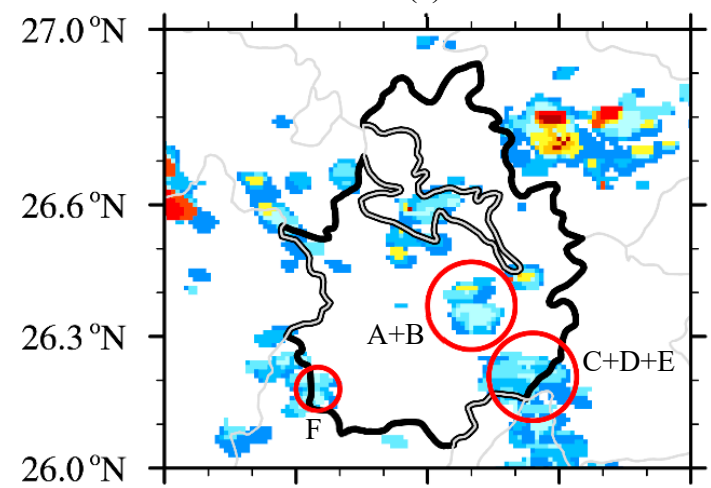

(e)

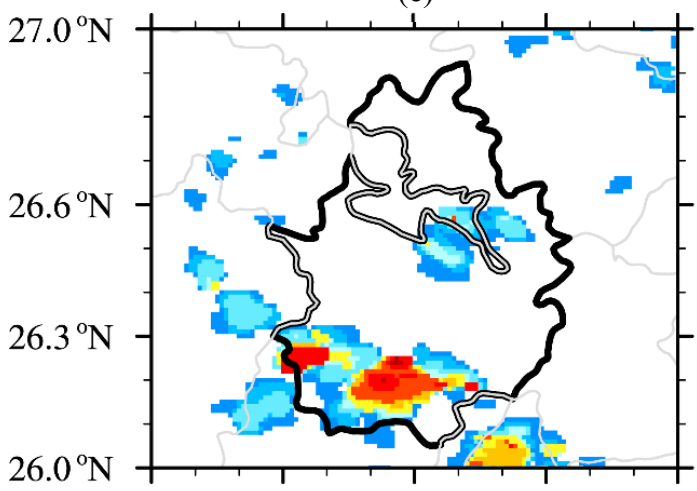

(b)

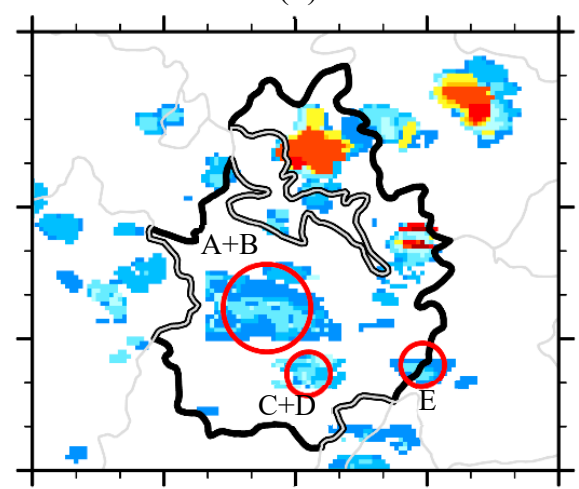

(d)

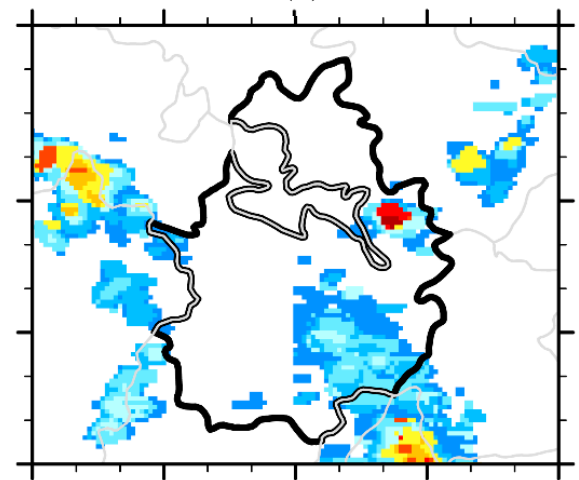

(f)

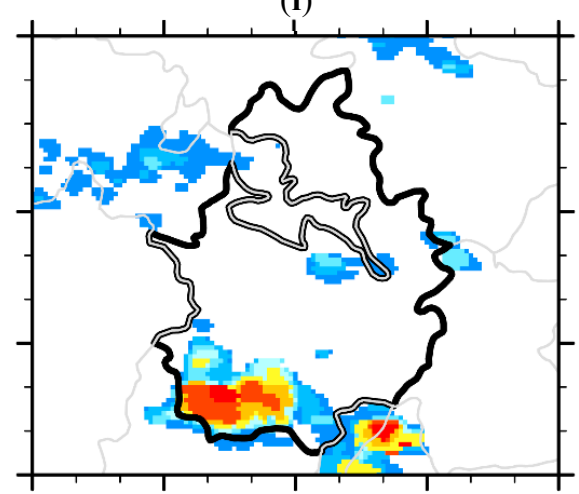

104.3 ${ }^{\circ} \mathrm{E} 104.6^{\circ} \mathrm{E} 104.9^{\circ} \mathrm{E} 105.2^{\circ} \mathrm{E} 105.5^{\circ} \mathrm{E} 104.3^{\circ} \mathrm{E} 104.6^{\circ} \mathrm{E} 104.9^{\circ} \mathrm{E} 105.2^{\circ} \mathrm{E} 105.5^{\circ} \mathrm{E}$
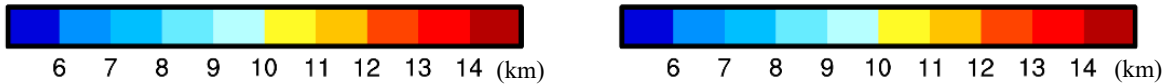

Figure 6. Radar maximum echo-top heights (shaded, $\mathrm{km}$ ) of three-dimensional mosaic data near Shuicheng County (a) from 09:00 to 10:00 UTC; (b) from 10:00 to 11:00 UTC; (c) from 11:00 to 12:00 UTC; (d) from 12:00 to 13:00 UTC; (e) from 13:00 to 14:00 UTC; (f) from 14:00 to 15:00 UTC on 22 July 2019. The letters in the figure represent the convective cells referenced in the main text.

During the synoptic-weather-related rainfall stage, there was stronger convective development in the valley region. Figure 7 provides the Plan Position Indicator (PPI) and Range Height Indicator (RHI) scans of the reflectivity and radial velocity to show the precipitation structure and corresponding local wind field information during the synoptic-weather-related rainfall stage. It should be noted that the $\mathrm{RHI}$ is reconstructed from the PPI volume scan, so it is not a true RHI scan; therefore, observations at different elevation angles will be temporally displaced. Larger reflectivity values exceeding $30 \mathrm{dBZ}$ were found over the valley terrain of Shuicheng County $120 \mathrm{~km}$ north of Xingyi in the PPI scans. Meanwhile, the RHI scan along the intense echo center could only observe these higher reflectivity values above $3.5 \mathrm{~km}$, and the echo-top height of the $18 \mathrm{dBZ}$ values approached $14 \mathrm{~km}$ (Figure $7 \mathrm{~b}$ ). 
In contrast to the reflectivity, a distinct convergence zone of the radial velocity was found along the echo belt, with an area of divergence to the north of the belt. The negative radial velocity zone was surrounded by a positive radial velocity zone, which indicates an adverse wind area (AWA) over Shuicheng County. AWAs are related to strong mesoscale convection, and the edge of the AWA corresponds to the heavy rain area [35]. On the RHI of the radial velocity, there is a distinct vertical convergence zone from 3.5 to $8 \mathrm{~km}$.

(a)

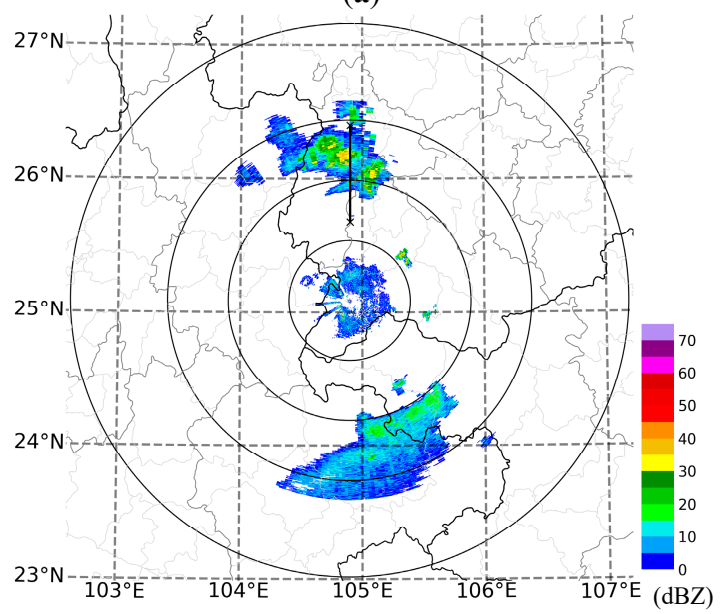

(c)

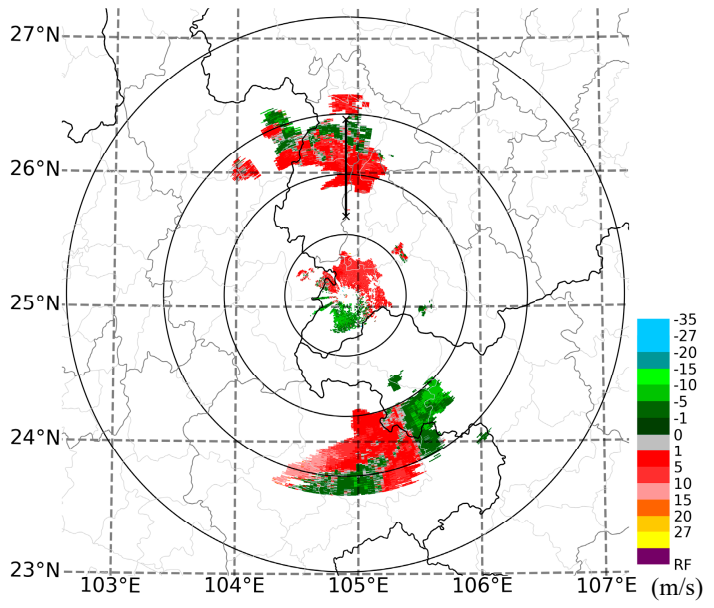

(b)

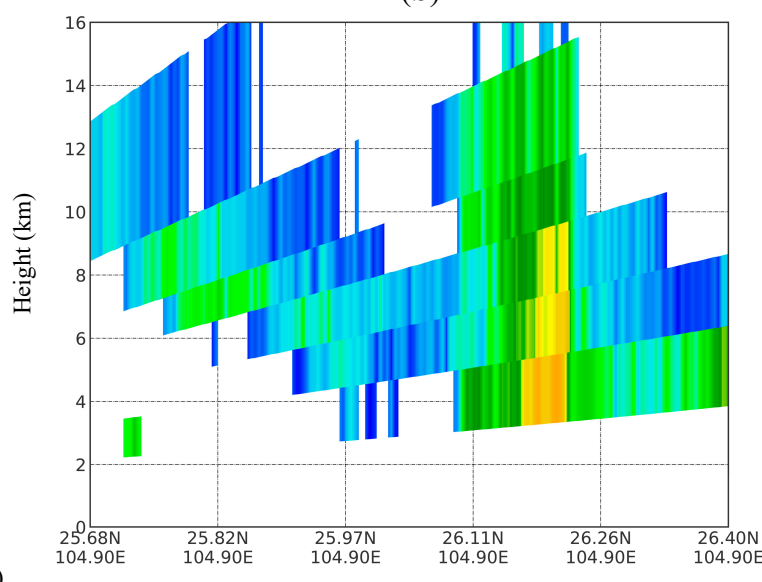

(d)

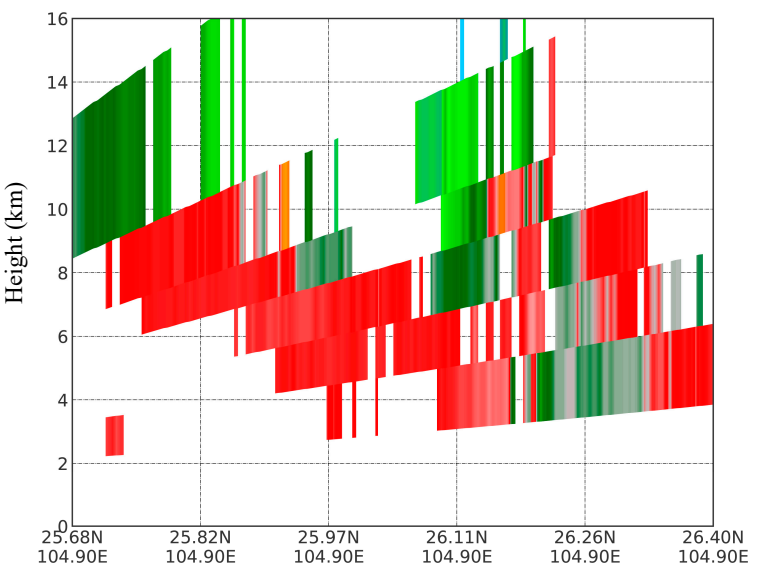

Figure 7. (a) Plan Position Indicator (PPI) reflectivity data and (c) radial velocity data collected by the Xingyi Doppler weather radar at an elevation of $1.5^{\circ}$ at 13:40 UTC on 22 July 2019. (b) Range Height Indicator (RHI) reflectivity and (d) radial velocity vertical cross-section along the solid lines in $(\mathbf{a}, \mathbf{c})$.

\subsection{Formation Mechanism of the AHRE}

To briefly show the formation mechanism of the AHRE during the two rainfall stages, Figure 8 shows the surface wind fields and equivalent potential temperature $\theta_{\mathrm{e}}$ fields during the two rainfall stages. $\theta_{\mathrm{e}}$ was used in this paper because it was calculated using air pressure, temperature, and dewpoint temperature, and its variation with time reflects the temperature and moisture content of air passing over a site [36]. At 09:00 UTC during the topographic rainfall stage, the stronger southeasterly winds surged into the "bellmouth" topography of Shuicheng County, and a weak local convergence zone developed in northern Shuicheng County. On the interpolated $\theta_{\mathrm{e}}$ fields, there were larger value areas of $\theta_{\mathrm{e}}$ in Shuicheng County, which corresponded to warm and moist areas. Therefore, we can conclude that the warm and moist southeasterly flow encountered the "bellmouth" topography of Shuicheng County that favors the generation of topographic rainfall. 
(a)

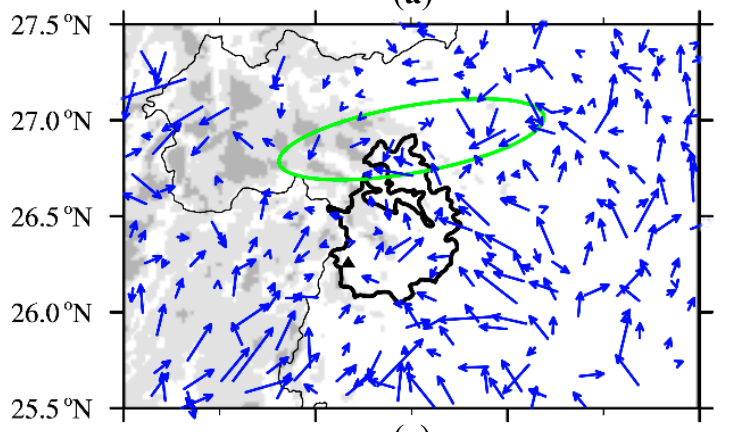

(c)

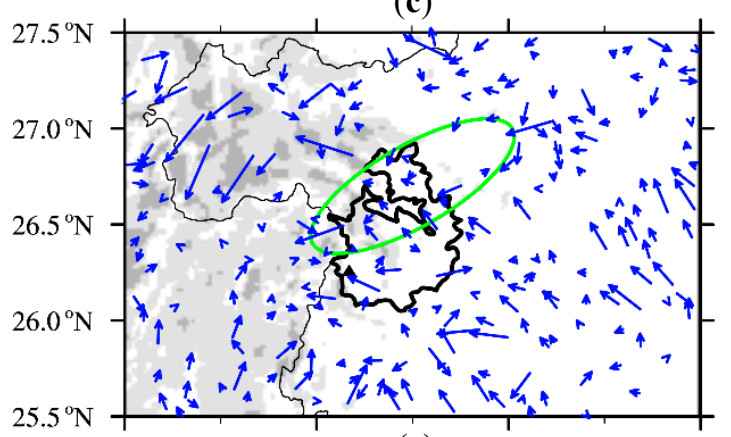

(e)

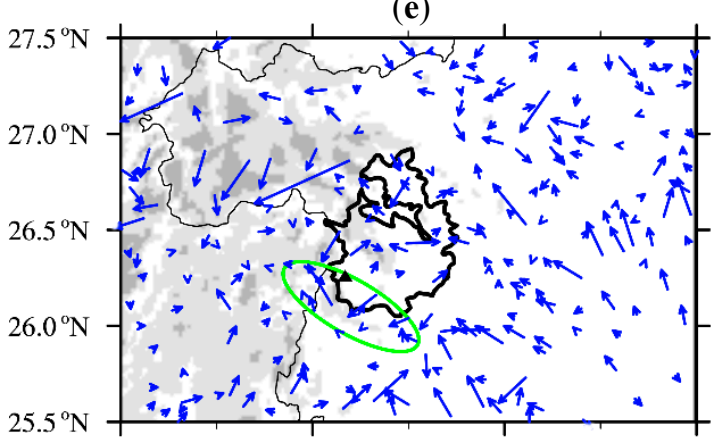

(b)

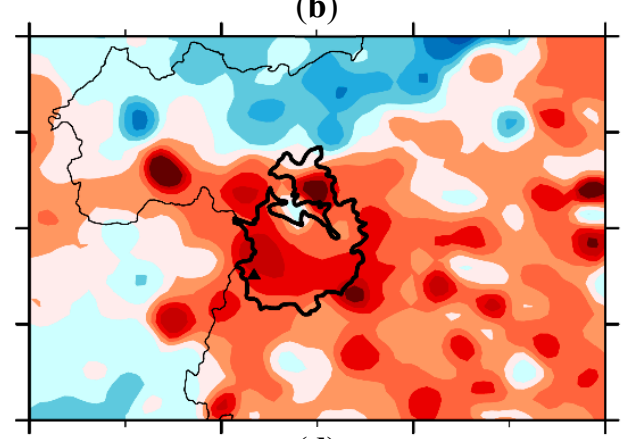

(d)

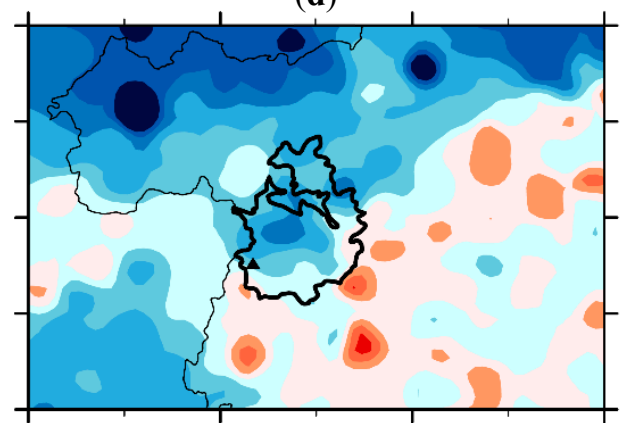

(f)

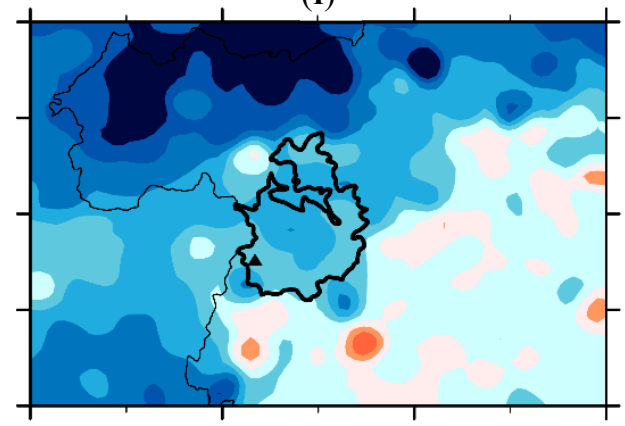

$106.5^{\circ} \mathrm{E}$
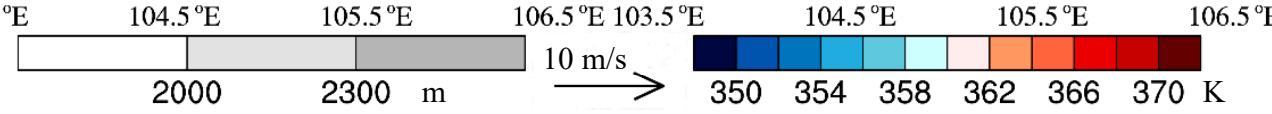

Figure 8. Distributions of the surface winds (blue vectors, units: $\mathrm{m} / \mathrm{s}$ ) and $\theta_{\mathrm{e}}$ (shaded, unit: $\mathrm{K}$, right) observed by automatic weather stations (AWSs) at (a,b) 09:00 UTC; (c,d) 12:00 UTC; (e,f) 13:40 UTC on 22 July 2019. The green circles denote the convergence regions, and shaded areas in the left panel denote the terrain height (units: $\mathrm{m}$ ).

Here, the warm and moist air flowing into the "bellmouth" topography formed a warm sector in the valley. Douglas [37] demonstrated that rain in the warm sectors of valleys plays a large and often dominant part in substantial orographic rainfall in the British Isles. At 12:00 UTC, before the synoptic-weather-related rainfall happened, the speed of the northeasterly winds increased and that of the southerly winds decreased, as the local convergence zone moved to the northwestern edge of the valley region. On the interpolated $\theta_{\mathrm{e}}$ fields, an obvious cold tongue that was caused by the northeasterly winds reached the northwestern edge of Shuicheng County. At 13:40, during the synoptic-weather-related rainfall stage, the local convergence zone was pushed to the southern border of Shuicheng County, and the $\theta_{\mathrm{e}}$ field indicated that the cold tongue became superimposed over the warm sector in the valley, which led to atmospheric convective instability. Houze [38] also noted that MCSs occurring near mountains are affected by the channeling of airflow near the mountains, capping the moist boundary layers by flow subsiding from the higher terrain.

From the above analysis, there are different environmental conditions and formation mechanisms during the two rainfall stages. During the topographic rainfall stage, isolated convective cells occurred 
in the southern warm and moist area with bigger $\theta_{\mathrm{e}}$ values. The topographic rainfall was caused by the interaction of the atmospheric flow with the terrain. During the synoptic-weather-related rainfall stage, a convective echo belt was enhanced when local convergence and a cold tongue reached the valley region in Shuicheng County. This indicates that a cold tongue from higher terrain superimposed over warm sectors in the bases of major mountain ranges could strengthen the rainfall in valleys.

\section{Summary}

Shuicheng County is characterized by locally complex terrain in the eastern Yunnan-Guizhou Plateau. At 09:00 to 16:00 UTC on 22 July 2019, an AHRE occurred in Shuicheng County. This event attracted significant attention in China because of the resulting serious natural disaster, which is unsuited for multiple large-scale numerical models to predict the small-scale orographic and convective components of the event. Additionally, the high-resolution mesoscale numerical model has not resolved the location and intensity of heavy rainfall over complex terrain. In this study, we used multiple observational datasets to provide support for understanding such an AHRE. First, based on the topography and observed precipitation distribution, the heavy rainfall over complex terrain showed two stages of location and intensity differences. Then, according to the spatiotemporal evolution and organizational characteristics of MCSs determined by combining surface and midlevel environmental field conditions, the AHRE was divided into two types: topographic rainfall and synoptic-weather-related rainfall. Next, multiple Doppler weather radars were utilized to depict radar echo characteristics during the two stages. Finally, surface AWSs and terrain data were used to analyze the surface wind, temperature, and humidity fields to briefly demonstrate the environmental conditions and formation mechanisms of the AHRE.

The observed precipitation showed that isolated rainfall centers occurred in the slope of the main peak during the early stage and that a stronger rainfall band located in the valley region between major mountain ranges occurred during the later stage. Upper-level observations of the MCSs by combining surface and middle-level environmental field conditions showed that different rainfall types affected the two stages of heavy rainfall in Shuicheng County. During the early stage, the body of the banded MCSs was located in northwestern Shuicheng County, while the southeasterly warm and moist air at the surface in front of the MCSs flowing into the "bellmouth" topography caused topographic rainfall. During the later stage, the banded MCSs split into two parts, and the southern MCS with intense cold core impacted Shuicheng County; the AHRE occurred due to the interaction of surface convergence and midlevel low-vortex systems.

An observational analysis of Doppler weather radar data showed that echo characteristics were also different during the two rainfall stages. During the topographic rainfall stage, smaller meso- $\gamma$-scale $(2-20 \mathrm{~km})$ convective cells with lower echo-top heights $(6-10 \mathrm{~km})$ occurred in the windward slope of the main peak; during the synoptic-weather-related rainfall stage, meso- $\beta$-scale $(20-200 \mathrm{~km})$ convective echo bands with higher echo-top heights $(10-14 \mathrm{~km})$ occurred in the valley. The terrain beam blockage also reduces the intensity of the observed radar reflectivity values. An AWA with distinct convergence of radial velocity existed over Shuicheng County.

The analysis of surface AWSs and terrain datasets showed that topographic rainfall occurred in the southern warm and moist area, while synoptic-weather-related rainfall occurred due to local convergence and the intrusion of a cold tongue. The superimposition of a cold tongue from the higher terrain over the warm sector at the base of the mountain range likely strengthened the rainfall.

The present study suggests that MCSs with different types of rain over complex terrain are important for forecasting AHREs, given the precipitation features and formation mechanisms of the AHRE considered herein from multiple observational datasets. However, this study lacked vertical observations of atmospheric environmental fields with higher resolutions, such as those from wind profile radar and sounding balloon observations, which provide additional wind, temperature, and humidity data at various pressure levels. In addition, data assimilation of in-storm Doppler weather radar reflectivity and radial velocity observations could be further utilized to initialize the mesoscale 
models and predict smaller-scale topographic rainfall. Additionally, high-resolution observations from the FY-4A, especially the horizontal gradients in environmental conditions could be very useful in obtaining more accurate representations of environmental conditions when assimilated in conjunction with radar observation.

Author Contributions: Conceptualization, G.L. (Guoping Li) and S.L.; Investigation, X.W.; Methodology, S.L.; Software, C.L.; Data resources, H.L. and G.L. (Gang Li); Supervision, G.L. (Guoping Li) and X.W.; Writing-original draft, S.L. All authors have read and agreed to the published version of the manuscript.

Funding: This work was supported by the National Key R\&D Program of China (Grant No. 2018YFC1507200), the National Natural Science Foundation of China (Grant Nos. 41975058, 91937301 and 91637211), and the Key Scientific and Technological Project of Hubei Meteorological Bureau (2019z03).

Acknowledgments: The authors are grateful to the China National Satellite Meteorological Center (NSMC) for proving FY-4A satellite data (http://satellite.nsmc.org.cn/), the U.S. National Oceanic and Atmospheric Administration (NOAA) for proving Global Land One-kilometer Base Elevation data (https://www.ngdc.noaa.gov/ $\mathrm{mgg} / \mathrm{topo} /$ ), and the Meteorological Observation Center of Guizhou Province for providing observational data.

Conflicts of Interest: The authors declare no conflict of interest.

\section{Appendix A}

(a) Observation

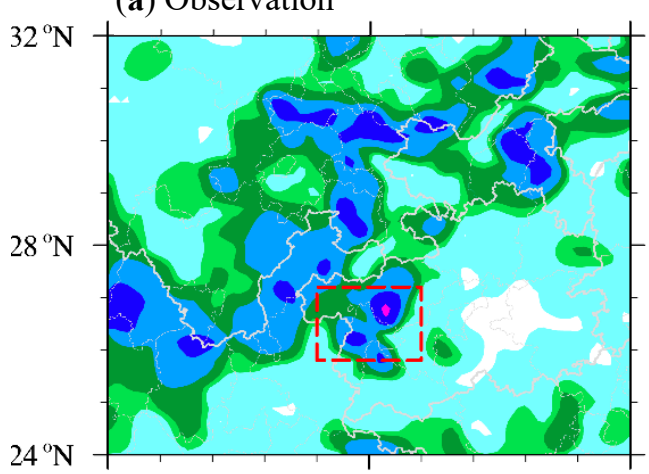

(c) ECMWF (b) CMA

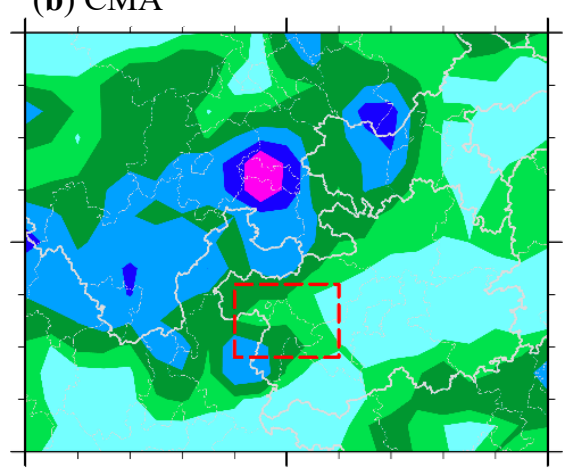

(d) NCEP

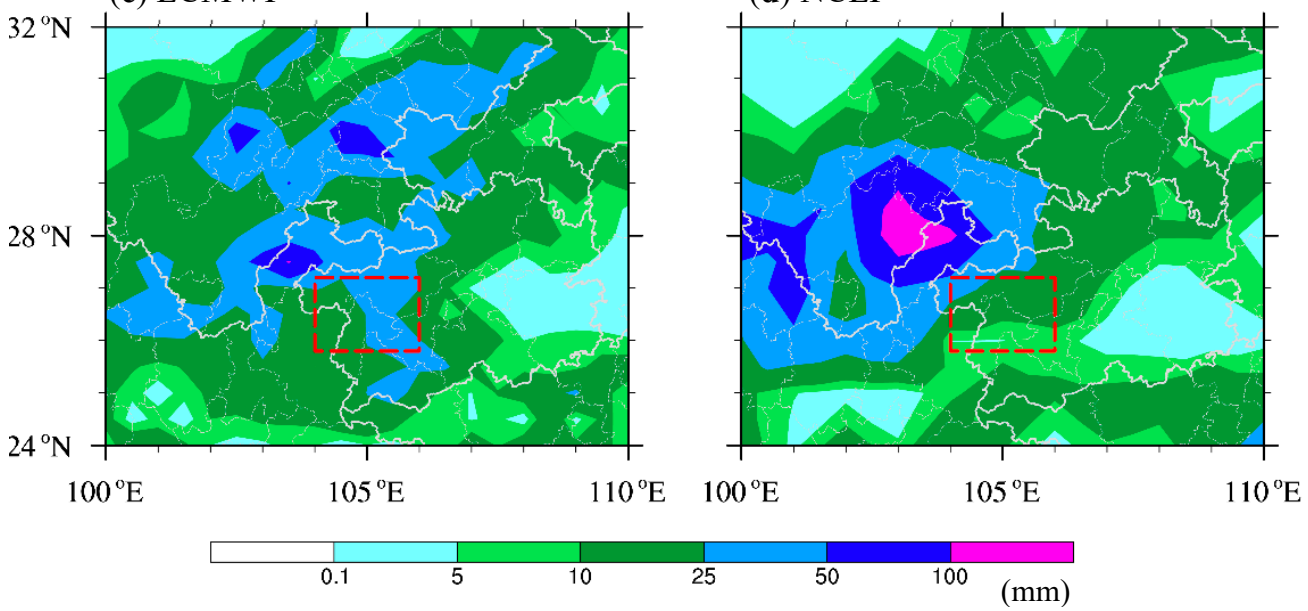

Figure A1. (a) Observational data, (b) the control forecast of the CMA (China Meteorological Administration), (c) the control forecast of ECMWF (European Center for Medium-Range Weather Forecasts), and (d) the control forecast of NCEP (National Centers for Environmental Prediction) for the 24-h accumulated precipitation on 22 July 2019 (unit: $\mathrm{mm}$ ). The lead time for the three models are 00:00 UTC on 22 July 2019. The above global models have horizontal resolution of $0.5^{\circ} \times 0.5^{\circ}$. The dashed-line red box outlines the area of interest in our study. 


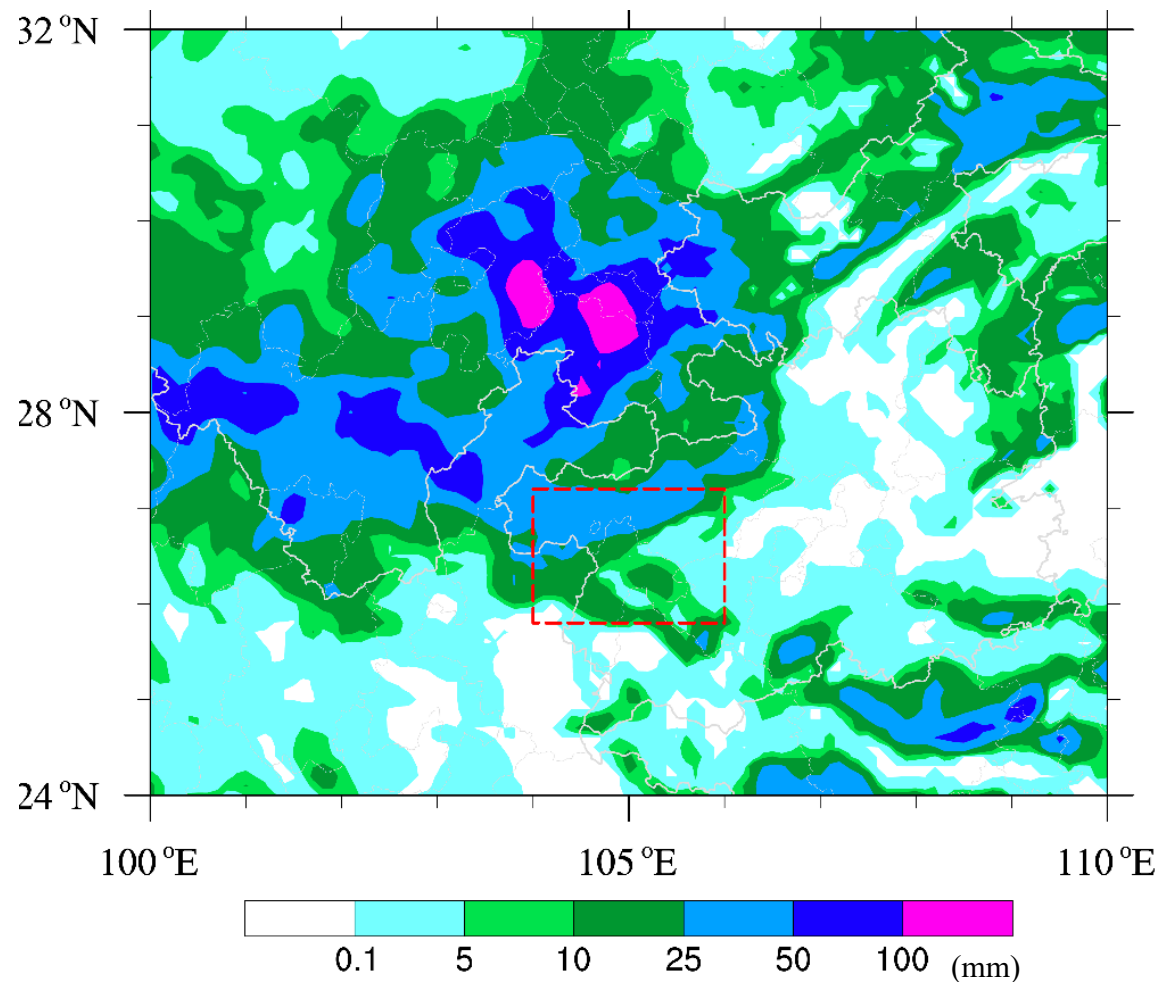

Figure A2. The high-resolution $\left(0.1^{\circ} \times 0.1^{\circ}\right.$ horizontal $)$ mesoscale model of Global/Regional Assimilation and Prediction Enhanced System (GRAPES_MESO) in China for the 24-h accumulated precipitation on 22 July 2019 (unit: $\mathrm{mm}$ ). The lead time is 00:00 UTC on 22 July 2019. The GRAPES has two forecast systems, i.e., GRAPES_GFS (global forecast system) and GRAPES_MESO (regional forecast system). The GRAPES_MESO has assimilated the observational data of FY-2E satellite but not Dopppler wather radar. The dashed-line red box outlines the area of interest in our study.

\section{References}

1. Chen, J.; Zheng, Y.G.; Zhang, X.L.; Zhu, P.J. Distribution and diurnal variation of warm-season short-duration heavy rainfall in relation to the MCSs in China. Acta Meteorol. Sin. 2013, 27, 868-888. [CrossRef]

2. Zhang, H.; Zhai, P.M. Temporal and spatial characteristics of extreme hourly precipitation over eastern China in the warm season. Adv. Atmos. Sci. 2011, 28, 1177-1183. [CrossRef]

3. Liu, C.Z. Genetic types of landslide and debris flow disasters in China. Geol. Rev. 2014, 60, 858-868. (In Chinese) [CrossRef]

4. Ren, D.D. The devastating Zhouqu storm-triggered debris flow of August 2010: Likely causes and possible trends in the future warming climate. J. Geophys. Res. Atmos. 2014, 119, 3643-3662. [CrossRef]

5. Kabeja, C.; Li, R.; Guo, J.P.; Rwatangabo, D.E.R.; Manyifika, M.; Gao, Z.; Wang, Y.; Zhang, Y. The impact of reforestation induced land cover change (1990-2017) on flood peak discharge using HEC-HMS hydrological model and satellite observation: A study in two mountain basins, China. Water 2020, 12, 1347. [CrossRef]

6. Zheng, Y.; Xue, M.; Li, B.; Chen, J.; Tao, Z.Y. Spatial characteristics of extreme rainfall over China with hourly through 24-hour accumulation periods based on national-level hourly rain gauge data. Adv. Atmos. Sci. 2016, 33, 1218-1232. [CrossRef]

7. Yu, R.; Li, J. Hourly rainfall changes in response to surface air temperature over eastern contiguous China. J. Clim. 2012, 25, 6851-6861. [CrossRef]

8. Schumacher, R.S.; Johnson, R.H. Organization and environmental properties of extreme-rain producing mesoscale convective systems. Mon. Weather Rev. 2005, 133, 961-976. [CrossRef]

9. Wang, Y.; Zhou, L. Observed trends in extreme precipitation events in China during 1961-2001 and the associated changes in large-scale circulation. Geophys. Res. Lett. 2005, 32, L09707. [CrossRef]

10. Smith, J.A.; Baeck, M.L.; Zhang, Y.; Doswell, C.A. Extreme rainfall and flooding from supercell thunderstorms. J. Hydrometeorol. 2001, 2, 469-489. [CrossRef] 
11. Luo, Y.; Wu, M.; Ren, F.; Li, J.; Wong, W.K. Synoptic situations of extreme hourly precipitation over China. J. Clim. 2016, 29, 8703-8719. [CrossRef]

12. Du, Y.; Chen, G. Heavy rainfall associated with double low-level jets over southern China. Part II: Convection initiation. Mon. Weather Rev. 2019, 147, 543-565. [CrossRef]

13. Chen, J.; He, W.; Yang, Q.; Lei, T.; Li, X.L.; Du, X.L. Effect of low-level eastward airflow on formation of severe precipitation on the east side of Fanjing Mountain. Torrential Rain Dis. 2020, 39, 158-166. (In Chinese) [CrossRef]

14. Chen, C.S.; Chen, W.S.; Deng, Z.S. A study of a mountain-generated precipitation system in northern Taiwan during TAMEX IOP 8. Mon. Weather Rev. 1991, 119, 2574-2606. [CrossRef]

15. Zhang, F.L.; Li, G.P.; Yue, J. The moisture sources and Transport processed for a sudden rainstorm associated with double low-level jets in the northeast Sichuan Basin of China. Atmosphere 2019, 10, 160. [CrossRef]

16. Gilewski, P.; Nawalany, M. Inter-comparison of rain-gauge, radar, and satellite (IMERG GPM) precipitation estimates performance for rainfall-runoff modeling in a mountains catchment in Poland. Water 2018, 10, 1665. [CrossRef]

17. Wijayarathne, D.; Coulibaly, P.; Boodoo, S.; Sills, D. Evaluation of radar-gauge merging techniques to be used in operational flood forecasting in urban watersheds. Water 2020, 12, 1494. [CrossRef]

18. Joss, J.; Waldvogel, A.; Collier, C.G. Precipitation measurement and hydrology. In Radar in Meteorology; America Meteorological Sociaty: Boston, MA, USA, 1990. [CrossRef]

19. PC, S.; Nakatani, T.; Misumi, R. The role of the spatial distribution of radar rainfall on hydrological modeling for an urbanized river basin in Japan. Water 2019, 11, 1703. [CrossRef]

20. Fu, Y.F.; Pan, X.; Tao, X.; Liu, G.S.; Li, R.; Wang, Y.; Ma, M. Precipitation characteristics over the steep slope of the Himalayas in rainy season observed by TRMM PR and VIRS. Clim. Dyn. 2018, 51, 1971-1989. [CrossRef]

21. Zhang, X.; Tang, J.; Wu, C.; Wu, D. An observational study of the inner core structure of Typhoon Meranti (2016) near landfall. Atmos. Sci. Lett. 2020, 21, e962. [CrossRef]

22. Yang, J.; Zhang, Z.Q.; Wei, C.Y.; Lu, F.; Guo, Q. Introducing the new generation of Chinese geostationary weather satellites-FengYun 4 (FY-4). Bull. Am. Meteorol. Soc. 2017, 98, 1637-1658. [CrossRef]

23. Zheng, Y.G.; Chen, J.; Zhu, P.J. Climatological distribution and diurnal variation of mesoscale convective system over China and its vicinity during summer. Chin. Sci. Bull. 2008, 53, 1574-1586. [CrossRef]

24. Feng, Z.; Dong, X.Q.; Xi, B.K.; McFarlane, S.A.; Kennedy, A.; Lin, B.; Minnis, P. Life cycle of midlatitude deep convective systems in a Lagrangian framework. J. Geophys. Res. Atmos. 2012, 117. [CrossRef]

25. Xiao, Y.J.; Liu, L.P.; Shi, Y. Study of methods for three-dimensional multiple-radar reflectivity mosaics. Acta Meteorol. Sin. 2008, 22, 351-361. [CrossRef]

26. Cui, W.; Dong, X.; Xi, B.; Liu, M. Cloud and precipitation properties of MCSs along the Meiyu frontal zone in central and southern China and their associated large-scale environments. J. Geophys. Res. Atmos. 2020, 125, e2019JD031601. [CrossRef]

27. Liu, L.P.; Wu, L.L.; Yang, Y.M. Development of fuzzy-logical two-step ground clutter detection algorithm. Acta Meteorol. Sin. 2007, 53, 252-260. (In Chinese) [CrossRef]

28. Xiao, Y.J.; Wan, Y.F.; Wang, Z.B. Quality control of dual PRF velocity data for Doppler weather radars. Plateau Meteorol. 2016, 35, 1112-1122. (In Chinese) [CrossRef]

29. Yang, L.; Smith, J.; Baeck, M.L.; Smith, B.; Tian, F.; Niyogi, D. Structure and evolution of flash flood producing storms in a small urban watershed. J. Geophys. Res. Atmos. 2016, 121, 3139-3152. [CrossRef]

30. Wang, J.Y.; Wang, X.F.; Wang, X.K.; Cui, C.G. Statistical characteristics of eastward propagation of cloud clusters from the Tibetan Plateau and mesoscale convective systems embedded in these cloud clusters. Chin. J. Atmos. Sci. 2019, 43, 1019-1040. (In Chinese) [CrossRef]

31. Houze, R.A. Monsoon convection in the Himalayan region as seen by the TRMM Precipitation Radar. Q. J. R. Meteorol. Soc. 2007, 133, 1389-1411. [CrossRef]

32. Soderholm, B.; Ronalds, B.; Kirshbaum, D.J. The evolution of convective storms initiated by an isolated mountain ridge. Mon. Weather Rev. 2014, 142, 1430-1451. [CrossRef]

33. Zhuang, W.; Liu, L.P.; Wang, G.L.; Cui, Z.H. Radar-derived quantitative precipitation estimation in complex terrain area in Qinghai-Xizang Plateau. Plateau Meteorol. 2013, 32, 1224-1235. (In Chinese) [CrossRef]

34. Shinoda, T.; Maki, R.; Shimizu, S.; Tsuboki, K.; Uyeda, H. Statistically features of precipitation cells observed in East Asia during the Meiyu/Baiu period. In Proceedings of the Conference on Mesoscale Meteorology and Typhoon in East Asian, Taipei, Taiwan, 6-8 November 2007. 
35. Xu, F.; Wang, B.N.; Xia, W.M.; Xu, Q. Analysis on characteristics of Doppler radar velocity in a heavy rain process in spring in Mid- and Lower-Reaches of Yangtza River Basin. Plateau Meteorol. 2014, 33, 548-556. (In Chinese) [CrossRef]

36. Obremski, J.S.; Samson, J.A.; Dutkiewicz, V.A.; Husain, L. On the use of surface equivalent potential temperature in isolating the influence of local as opposed to transported sources on aerosol concentrations. J. Geophys. Res. 1989, 94, 11117-11127. [CrossRef]

37. Douglas, C.K.M.; Glasspoole, J. Meteorological conditions in heavy orographic rainfall in the British Isles. Q. J. R. Meteorol. Soc. 1947, 73, 11-42. [CrossRef]

38. Houze, R.A. Orographic effects on precipitating cloud. Rev. Geophys. 2012, 50, RG1001. [CrossRef]

(C) 2020 by the authors. Licensee MDPI, Basel, Switzerland. This article is an open access article distributed under the terms and conditions of the Creative Commons Attribution (CC BY) license (http://creativecommons.org/licenses/by/4.0/). 